\title{
State expenditure and its finance
}

\author{
Effects on macroeconomic surplus-value and on the distribution of income \\ and wealth
}

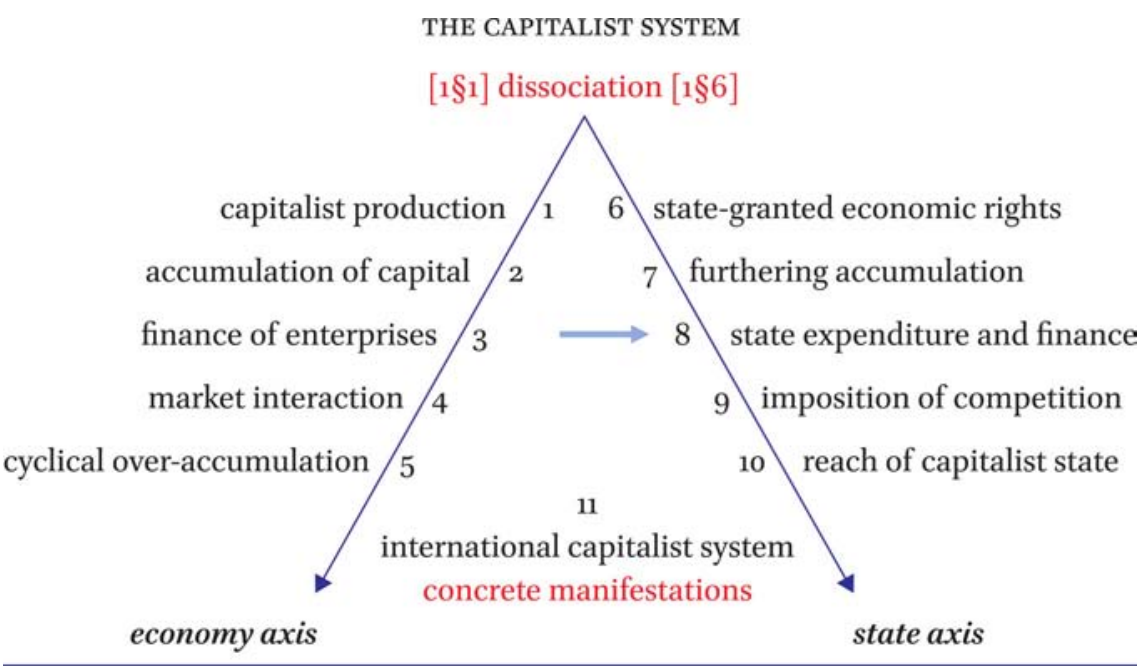

\section{Contents}

Introduction $\quad 387$

Division 1. State production and state expenditure $\quad 389$

$8 \S 1 \quad$ Production in monetary terms by state-employed labour ('civil servants') $\quad 389$

$8 \S 2$ The state's action in terms of state expenditure 391

$8 \S 3$ State production in terms of quantity of employment: state employment 393

Division 2. The finance of the state: taxation and other main forms of finance

$8 \S 4$ Taxation and other main forms of finance of the state 394

Division 3. The effect of state expenditure on the enterprises' production and validation of surplus-value: macroeconomic expenditure 398

$8 \S 5$ State expenditure and production of enterprises 398

$8 \S 6 \quad$ State expenditure and macroeconomic surplus-value 399

(C) GEERT REUTEN, 2019 | DOI:10.1163/9789004392809_011

This is an open access chapter distributed under the terms of the prevailing CC-BY-NC-ND License at the time of publication. 
Division 4. The combined effect of state expenditure and taxation on the enterprises' after tax surplus-value 407

$8 \$ 7 \quad$ A profits tax: taxation of surplus-value 407

$8 \S 8$ The effect of a fiscal deficit of the state on the after tax surplus-value 409 Division 5. Forms of taxation: the distribution of income and wealth 412

$8 \S 9$ The finance of social security: taxes and social security contributions 412

$8 \S 10$ Forms of taxation 415

$8 \S 11$ Forms and design of taxation, and their legitimation in compliance to a particular distribution of income $\quad 416$

$8 \S 12$ The after-tax resulting distribution of wealth 424 Summary and conclusions 433

Appendix 8.A. Data and data sources of the graphs in chapter $8 \quad 435$ List of figures chapter $8 \quad 439$ 


\section{Introduction}

Chapters 6-7 set out why, and in what respect, the capitalist economy cannot possibly exist without the state. Those chapters focused on the necessary content of the state's activities. Chapter 8 focuses on those activities in terms of monetary expenditures of the state and of their finance, outlining in particular their effect on the profits of enterprises.

In economic terms the state 'produces' its activities, requiring wage labour (civil servants) as well as inputs from enterprises. The concomitant expenditures are a category distinct from the expenditures related to transfers, such as those on social security. (Division 1.)

Division 2 presents a general outline of the finance of the production- and transfers-related expenditures by way of taxation and other forms of finance.

The following two divisions present the effect of state expenditure on the macroeconomic surplus-value of enterprises (Division 3) and of taxation on their after-tax surplus-value (Division 4). Along with it the so-called 'tax burden' for enterprises will be presented in a different light from how it is usually perceived.

Taxation being necessary, the state can and must choose between several forms of taxation and combinations thereof. This implies that in terms of the methodological pair of necessity and contingency, necessity in this respect (finance, taxation) takes on a contingent form. This form is determined by the state's furthering of the conditions for the accumulation of capital as articulated with its legitimation requirements. The particular forms of taxation result in a particular distribution of income (skewed) and in a particular distribution of wealth (even more skewed). (Division 5.)

Division 1 (state production) and Division 2 (finance of the state) provide conditions of existence for the exposition of Chapters $6-7$. All the other divisions have the status of concretising implications of these earlier chapters and divisions. Scheme 8.1 presents the chapter outline.

In amplifications to sections of this chapter, the reader finds empirical illustrations in reference to averages of 21 current OECD countries, extending where possible to 1870 . The reader is referred to Appendix $6 \mathrm{~A}$ for the status of these illustrations and especially the point that the OECD-21 average is meant to represent capitalism in its strongest version in terms of the reproduction of the capitalist system. ${ }^{1}$

1 Generally I repeat that cognisance of the Amplifications and Addenda is not required for the understanding of the further text (main sections and Explications). 
SCHEME 8.1 State expenditure and its finance (outline Chapter 8)

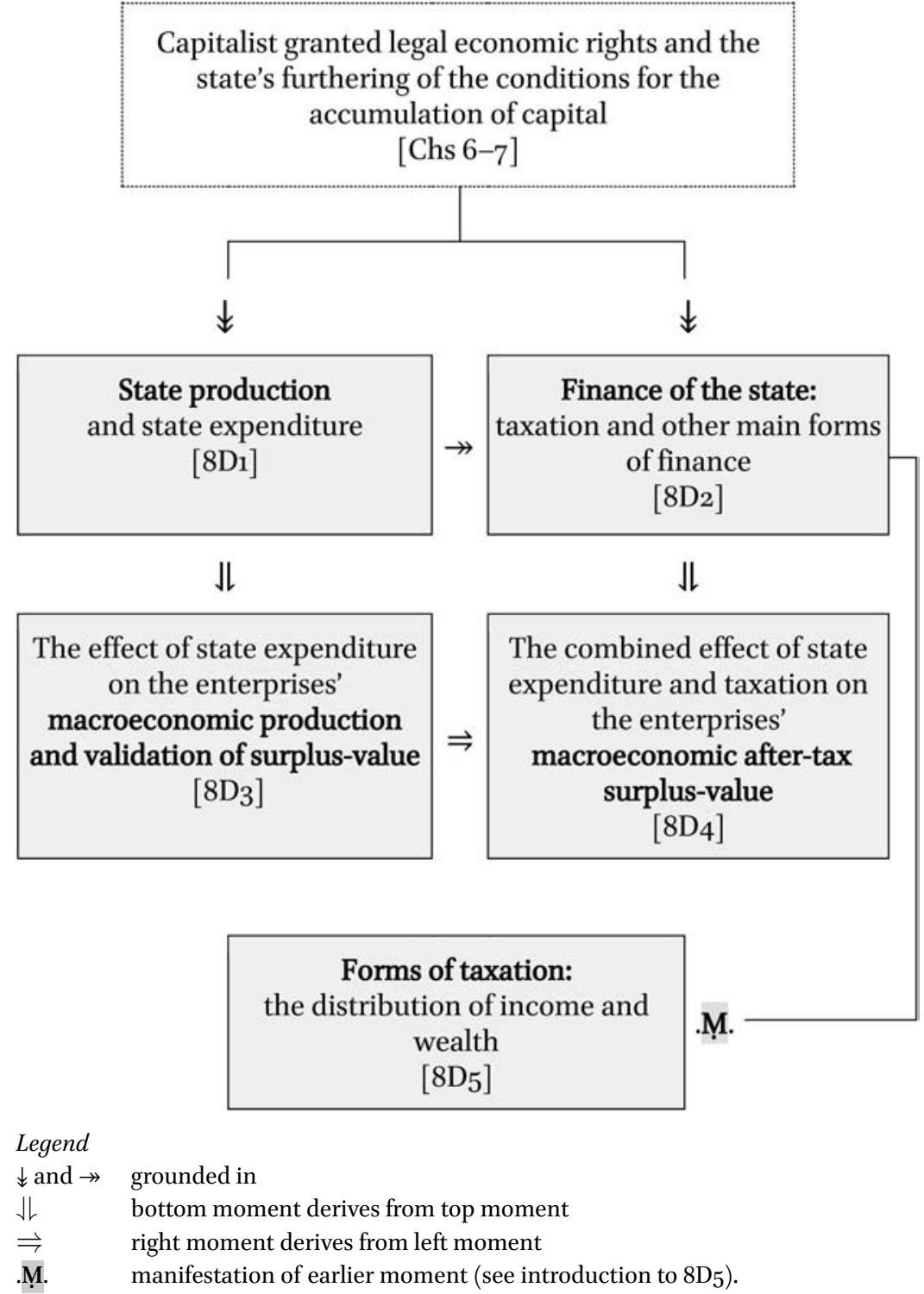




\section{Division 1. State production and state expenditure}

This division grounds the previous exposition of the state in its 'production'. In Chapters 6-7 the primary focus was on the content of the state's legislative frameworks. The information in Amplifications of Chapter 7 on expenditures on these frameworks was in fact presented as an aside. The following two divisions focus on the state as being also an economic actor. In the current division the perspective is that of 'state production' and of 'state expenditure' in general.

\section{$8 \S 1 \quad$ Production in monetary terms by state-employed labour ('civil servants')}

Chapters $6-7$ presented the capitalist state's granting of economic and existence claims in the form of legal rights $\left(6 \mathrm{D}_{2}-6 \mathrm{D}_{3}\right)$ and their concretisation (6D4-6D6), its frameworks furthering of the conditions for the accumulation of capital $\left({ }_{7} \mathrm{D}_{2}-7 \mathrm{D}_{4}\right)$ and its compliance-dependent social security provisions $\left({ }_{7} \mathrm{D}_{5}\right)$. In brief this is the content of the seven legislative frameworks presented in these chapters.

Economically the state 'produces' the content of the seven frameworks, this production being a condition of existence (ground) for these frameworks. For this production the state employs wage labour (wages sum Wg). For it, the state also purchases inputs from enterprises, both floating inputs (such as paper, transport and cleaning) and replacement investment (together Fg). (Net investment is presented in $8 \S 2$.) In monetary terms the product of the state's labour is a set of collective goods and services $\left(\mathrm{G}^{\mathrm{coL}}\right)$ :

$$
\mathrm{G}^{\mathrm{COL}}=\mathrm{Fg}+\mathrm{Wg}
$$

$$
\text { [convention of the state] }
$$

(I denote state monetary entities by the symbol $\mathrm{G}$ or $\mathrm{g}$, for government, so avoiding any confusion with the symbol $S$ for savings.)

The state tends to have its labour (also called 'civil servants') produce these frameworks on a pure costs basis. Thus, in contradistinction to enterprises, the state tends to make no profits, whence wages are the sole component of its value-added (Yg).

$$
\mathrm{Yg}=\mathrm{Wg}
$$

$$
\text { [convention of the state] }
$$

The reason for this is largely that it cannot sell to individuals most of its activities (e.g. legislation and public security), which so are collectively provided or distributed for free. Even if the state generally does not sell its production, it nevertheless partakes in the capitalist economy's monetary-value dimension and it so calculates its activities in monetary terms from their costs perspective. $^{2}$

2 This is different from commensuration and from ideal pre-commensuration of the output of commodities ( $1 \S 4$ and $1 \S 10)$. 
Given some quantitative level of $\mathrm{G}^{\mathrm{col}}$ (defined by $\mathrm{Fg}$ and $\mathrm{Wg}$ ), the relative division between the purchases $\mathrm{Fg}$ and the $\mathrm{Wg}$ depend on the state's contingent preferences and ideological stance. (For example, when the state itself no longer undertakes road construction, but instead moves to purchasing roads from private enterprises, Fg increases and Wg declines. However, if the state labour and the private labour is equally productive then - for the same lot of roads - state expenditure must increase because enterprises require profit.)

Equation (8.1) regards the production of the state, not the expenditures on various transfers that do not relate to its own production - a main transfer category being that of social security transfers (see $8 \S 2$ ).

8§1-a Addendum. The (non-)surplus-value producing character of the labour of civil servants

In the state's accounts the value of $\mathrm{G}^{\mathrm{coL}}$ is defined by the values of $\mathrm{Fg}$ and $\mathrm{Wg}$ ! There is no reason to assume that civil servants are less (or more) exploited than privately employed labourers in physical terms, even if we have no proper measure to account for it. Assuming that state labour is equally productive as the labour employed by enterprises, it is likely that it contains a surplus component, whence 'the value' of $\mathrm{G}^{\mathrm{CoL}}$ would be underrated in the System of National Accounts. Even if the labour product of civil servants were to (implicitly) contain a surplus component (i.e. the difference between the wage and the net product of, e.g., legislation or policing), this surplus is in fact distributed for free over production enterprises, financial enterprises and households (collective goods and services). ${ }^{3}$

Another matter is the appropriation of the (macro)economic surplus-value. Abstracting from any public ownership of capitalist enterprises (selling their output via the market) there is no surplus-value other than that appropriated by enterprises (including that which enterprises distribute to financiers). Thus any state production of a surplus (if there were such a thing) is expressed in the surplus-value of enterprises.

Relevant in this respect is the particular implicit allocation of state services, amongst others, over particular branches of enterprises. Regarding infrastructural works, for example, some branches benefit more directly than others from these being distributed for free. However, the matter of this non-market allocation seems independent of a particular theory of value. Generally we can only

3 This assumes that generally there is no direct link (in the sense of prices being a direct link) between particular taxes and particular state services. In this sense the latter are distributed for free. 
say something about it in very rough, imprecise, terms of implicit subsidies even if in some cases some aspects of the allocation can be market mimicked (think of port dues).

\section{$8 \S 2 \quad$ The state's action in terms of state expenditure}

The production by the state $(8 \S 1)$ is conditioned by its monetary expenditure on wages and floating inputs from enterprises. The state's production also requires expenditure on investment input from enterprises. Thus we have the following production related expenditure:

- wages of civil servants (Wg);

- floating inputs from enterprises $(\mathrm{Fg})$;

- investment inputs from enterprises (Ig). ${ }^{4}$

Other expenditures - not state-production related - include various transfers:

- Legitimating social security transfers $(\mathrm{Zg})$ - as indicated in $7 \mathrm{D}_{5}$, their level depends on compliance requirements;

- Interest payments on the state debt $[\mathrm{Qg}]$. These are monetary flows from the state to its creditors, i.e. its financiers such as banks and capital owners.

- Subsidies to enterprises, to households and to cultural institutions. I call these transfers 'amenities' (Ag). These contingent subsidies are neglected in this chapter (briefly amplified on in 10§13).

Hence we have the following sum of state expenditure $\left(G^{*}\right.$ and $\left.G\right)$ : $\mathrm{G}^{*}=(\mathrm{Wg}+\mathrm{Fg})+\mathrm{Ig}+(\mathrm{Qg}+\mathrm{Zg})+\mathrm{Ag} \quad$ [accounting definition] (8.3Ag) For the purposes of this chapter we have (Ag neglected):

$$
\mathrm{G}=(\mathrm{Wg}+\mathrm{Fg})+\mathrm{Ig}+(\mathrm{Qg}+\mathrm{Zg}) \quad \text { [definition] }
$$

$8 \S 2-\mathrm{a} \quad$ Amplification. The trend in total state expenditure of the OECD-21 from $1870-2015$

Graph 8.2 shows total state expenditure as a percentage of GDP from 1870 to the present for the average of the current 'OECD-21' (see Appendix $6 \mathrm{~A}$ on the OECD-21). These include the amenities in equation (8.3Ag) - about $7 \%$ of GDP in 2015 (see $10 \$ 13-\mathrm{Ag}$ being the sum of 'general amenities' and 'subsidies and other direct assistance for enterprises').

4 Contingently some enterprises might be state owned, whilst operating on the market. This does not affect the categories of expenditures. In that case any distributed profits flow to the state in the form of dividends. Contingently the state might also undertake a variety works such as the construction of roads or parks or the collection of garbage by its own staff. In this case the state's expenditures on wages $(\mathrm{Wg})$ and on investment $(\mathrm{Ig})$ are higher and those on floating inputs from enterprises $(\mathrm{Fg}$ ) lower (though these works will always require the purchase of commodities from the private sector). This is a main reason why this chapter focuses on the total state expenditure $(G)$. 
State expenditure as a percentage of GDP more than doubled between 1870 and 1937 (from 11 to $24 \%$ of GDP) and then again nearly doubled between 1937 and 1990 (to $45 \%$ of GDP). It then decreases (to $42 \%$ ) until the outbreak of the financial crisis in 2007-08. The fastest increase occurs between 1913 and 1920, followed by the period $1960-80.5$

Generally, data for all of the OECD-21 prior to 1960 are scarce. Therefore as mentioned in $7 \S 14-\mathrm{e}$ - in order to show the possible impact of the scarce number of data for earlier years, most of my long run graphs show series for separate numbers of countries.

Note for Graph 8.2 (and for other similar graphs to come) that the measure of GDP share blends out variations in GDP itself. This is especially relevant for the severe recessions of the 1930s, of the early 198 os and of 2008 to about 2013. In this respect note also that cycles do not run synchronous internationally.

GRAPH 8.2 Total state expenditure (general government) 1870-2015, in \% GDP; average of 10 to 21 current OECD countries

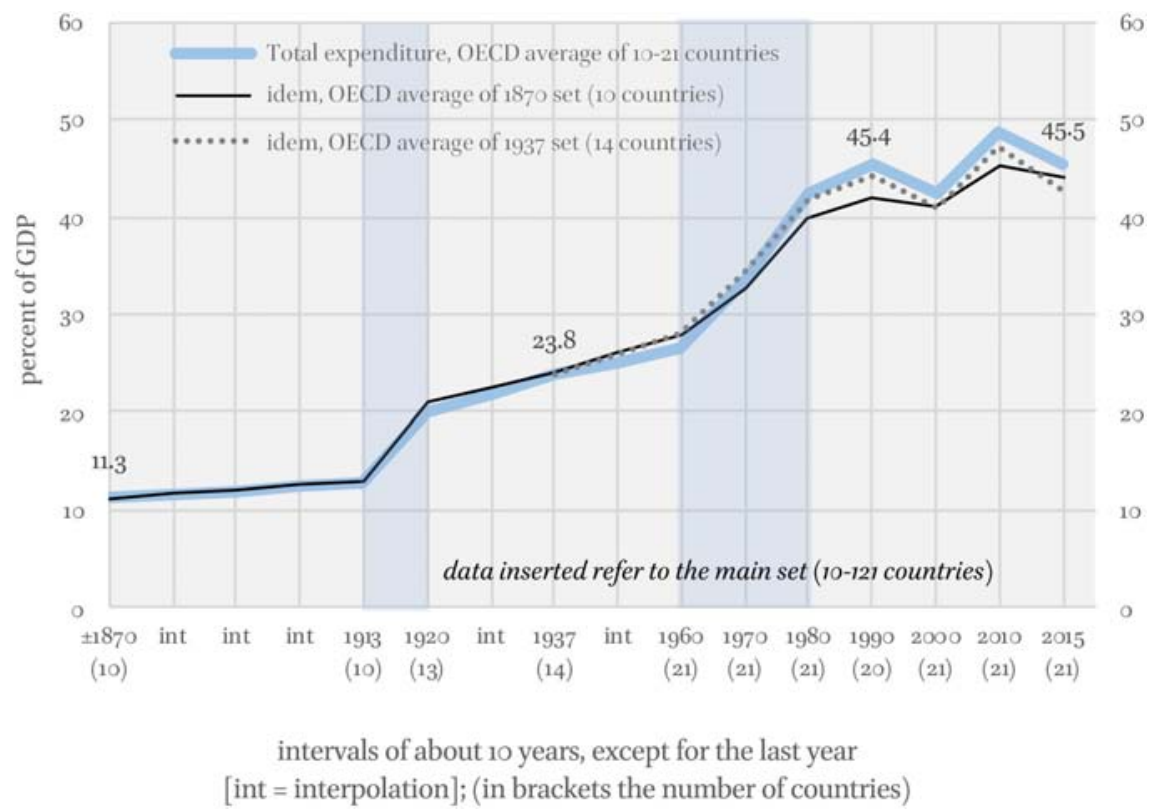

DATA SOURCES: 1870-1937 (Tanzi and Schuknecht 200o); 196o-80 (Castles 20o6); from 1990 onwards (OECD dataset Economic Outlook, November 2017; extracted 28 December 2017). For details see Appendix 8.A under 8§2-a

5 Although World War I expenditures play a role in the period 1913-20, there has been, on average, no cut back between $1920-37$ and after until about 1995 . 


\section{$8 \S 3 \quad$ State production in terms of quantity of employment: state employment}

Because the state produces no surplus-value - or does not account for it $(8 \S 1)$ gross or net value-added provides no adequate measure for state production in comparison with private production. For that comparison the share of state employment in total employment is a more adequate measure.

8§3-a Amplification. State employment in the OECD-21

Graph 8.3 shows the share of state employment in total employment for an average of the OECD-21 between 1870 and 2015. The data that are used exclude military employment and employment in state-owned enterprises because of the contingency of these categories. ${ }^{6}$ We see that this share of state employment in total employment - after a steep increase between 1937 and 1980 stabilised after 1980 at about $19 \%$ of total employment. The graph shows this state employment in comparison with the state expenditure of Graph 8.3 (note thus their different bases of total employment and GDP).

\section{8§3-b Amplification. Outsourcing of state functions}

In ${ }_{10 D}$ the major components of the bending in state expenditure will be shown. Here I briefly consider a quantitatively minor, though ideologically important, component, which is the state's (states') outsourcing of part of its (their) 'functions', including outsourcing in the form of licences. Minor, because education and social security expenditures are the largest components. This outsourcing has often been defended in terms of cost efficiency (private enterprises would produce cheaper). Examples range from road and rail construction and public transport to maintenance of public parks and monuments. This implies a moderation of state employment, but not necessarily a more than proportional expenditure moderation. ${ }^{7}$

6 In the early years of the twenty-first century, the employment in state-owned enterprises amounted, for the OECD-21 on average, to around $2 \%$ of the economy's total employment (see OECD, Government at a Glance 2013).

7 The two main factors that account for this are the procurement costs and the profits that private enterprises require. Regarding these expenditures a key question is whether any possible production efficiency gain would outweigh the profits and the procurement cost. However, supposed gains may not be the primary motive for outsourcing. A primary motive might be a factional ideological principle that what private enterprises might do should not be undertaken by the state. Again, such a principle may affect the size of state production, though not necessarily the proportional or more than proportional size of state expenditure and taxation. 
GRAPH 8.3 State employment as percentage of total employment ${ }^{8}$ in comparison with state expenditure (each general government); averages of up to 21 current OECD countries, 1870-2015

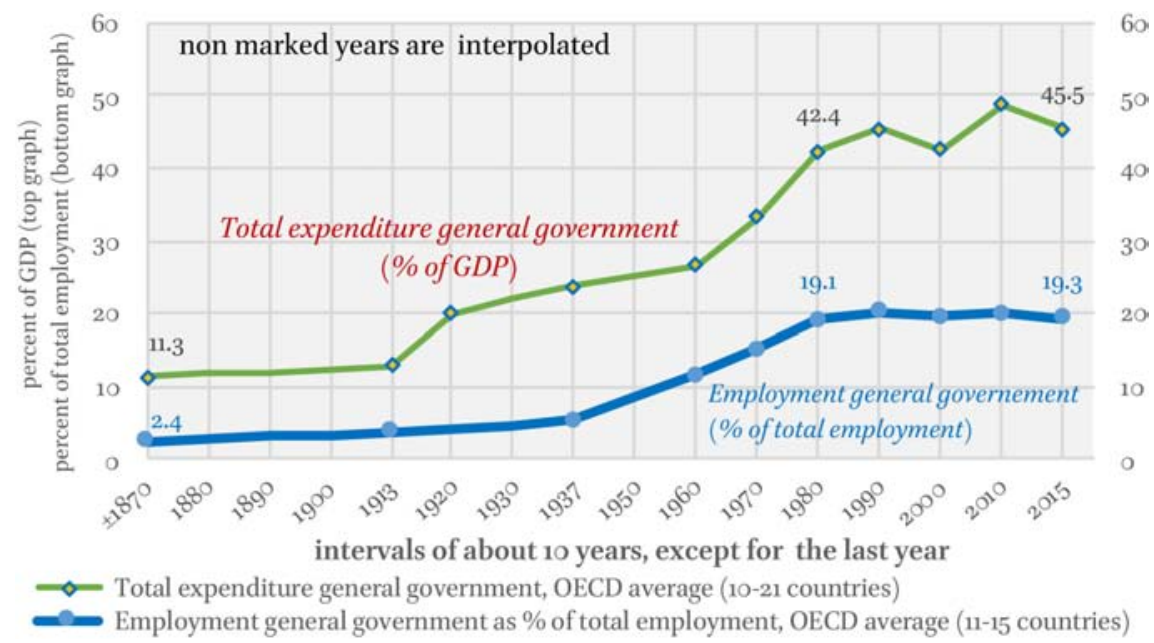

DATA SOURCES: for top line see Graph 8.2; for bottom line: 1870, 1913, 1937 (Tanzi and Schuknecht 2000); 1960 (OECD 1999); 1970-2015 (OECD dataset Economic Outlook, November 2017; extracted 28 December 2017). For further details on the bottom one, see Appendix 8.A under $8 \S 3$

\section{Division 2. The finance of the state: taxation and other main forms of finance}

As in the previous division the current division focuses on the state as being also an economic actor. This division grounds the previous two chapters, and particularly also the moment of state production and expenditure (8D1), in the finance of the state.

\section{$8 \S 4 \quad$ Taxation and other main forms of finance of the state}

We have seen that taxation is necessary for the existence of the capitalist state and hence of the capitalist system (7D1). Whereas taxation so is a necessary form of finance of the state, its required amount can contingently be moderated by other forms of finance. A particular category amongst these is that of 'social security contributions' (see further $8 \$ 9$ ). Contingently, taxation can also

8 Employment general government (excluding military employment and employment by public corporations) as a percentage of total employment (persons, civilian). 
be moderated by state borrowing (see further $8 \S 4-\mathrm{a})$. Then we have for the 'current finance of expenditure' $(\mathrm{CFg})$ :

$\mathrm{CFg}=\mathrm{T}+\mathrm{SSC}+\mathrm{OR}+\mathrm{B}$ [accounting definition] (8.4) where $T$ is the sum of taxes, ssC social security contributions, OR other receipts and $B$ is the net current borrowing flow. B is negative in case of a fiscal surplus. In all cases we have:

$\mathrm{CFg}=\mathrm{G}$ [accounting definition] (8.5) where $\mathrm{G}$ denotes state expenditure. $\mathrm{CFg}$ and $\mathrm{G}$ are net categories. This means that if the state itself pays any taxes (which are recollected by the state's treasury), these would be deducted from each side of the 'gross budget' to reach the net budget. Similarly, the current borrowing flow B is net, meaning that in case the state at the same time (year) borrows and lends, these are netted.

8§4-a Amplification. The contingent forms of finance other than taxation and social security contributions

Division 5 expands on the finance of social security transfers, including social security contributions $(8 \S 9)$ and on the various forms of taxation ( $8 \S 10)$. The current amplification sums up the forms of finance other than taxation and ssc. All of these other forms are contingent.

\section{- Borrowing}

In order to finance its expenditures - and especially in order to finance temporary extra expenditures as well as investment expenditures - the state may borrow from banks, from other financial institutions, from enterprises with temporary surplus funds and from rich individuals. This can be short-term borrowing through the issuance of treasury bills, or also medium- to long-term borrowing through the issuance of bonds.

Recall that any new borrowing of money (that is, any macroeconomic increase in the sum of money borrowed) must derive from money creation by banks and so originates with banks $(2 \S 8,3 \S 2)$. The state may also borrow from the Central Bank concomitantly on which the latter creates money $(7 \S 4)$.

Although in practice both 'temporary' extra expenditures and investment expenditures can be flexibly defined, the general idea is that the costs of these expenditures are recovered from future tax amounts without raising tax rates now.

This borrowing itself might approach a quasi-form of taxation to the extent that the rate of inflation increases, or increases above its expected rate. ${ }^{9}$

9 Inflation indexed rates of interest may prevent this implicit quasi-taxation. 


\section{- Enforced lending}

Borrowing by the state other than for the finance of temporary extra expenditures as well as investment expenditures (see above) can be considered as a postponement of taxation. However, when the state manages to issue perpetual bonds (consols) taxation is postponed indefinitely. ${ }^{10}$ Enforced perpetual lending at a (near to) zero rate of interest approaches taxation.

- Royalties on licences

In principle, royalties on licences could be extended for any (commercial) activity. The broader its base, the more it approaches a quasi-taxation.

- Sale of state services, often in the form of dues

- Dividends on state-owned enterprises

- Rent on state-owned property including land

The degree to which these latter three might contingently substitute for taxation depends on the state's economic constellation in this respect.

- Fines

In $7 \S_{2}$ I introduced the fundamental conflict of taxation, in that it overrides property rights. Some of the other finance categories mentioned may also be conflicting. This applies especially to state-owned enterprises when these are considered to compete with private enterprises. This may be different when state-owned enterprises are restricted either to specific sectors (such as banking or power provision) or enterprises with (potential) extreme market power (e.g. monopolies).

In any case within capitalism it is not plausible that the state might finance its expenditure without any taxation, and empirically this has not been the case.

8§4-b Amplification. The trend in taxes and other state receipts in the OECD-21, 1870-2015

Graph 8.4 shows the trend in total state receipts from 1870 to 2015 (current OECD-21 average) as a percentage of GDP.

The average of the total state receipts quadrupled between 1870 and 2015 (from nearly 11 to $43 \%$ of GDP). The fastest increase occurs between 1913 and $1920(12 \%$ to $19 \%)$, and from 1937 to $1970(18 \%$ to $35 \%)$. After 1970 the rates of increase gradually fade off. For the early decades data are available only for $7-8$ countries. However, it can be seen from the thin solid line in the graph that the data for the 8 countries of 187 o roughly approximate those of the up to 21 coun-

\footnotetext{
10 For a brief description of British consols see http://en.wikipedia.org/wiki/Consol_(bond). On enforced temporary lending see a 2012 proposal by the German DwI: http://www.diw .de/documents/publikationen/73/diw_o1.c.405701.de/12-28-1.pdf; for an abstract in English see http://www.diw.de/sixcms/detail.php?id=diw_o1.c.405712.de.
} 
tries afterwards. From 1965 more specific data are available for tax and social security receipt (the two dotted lines). We see that the growth of these bends off after 2000 .

GRAPH 8.4 State receipts (general government) 1870-2015, in \% GDP: (a) total current receipts; (b) tax and social security receipts; (c) tax receipts. Averages of 8-21 current OECD countries

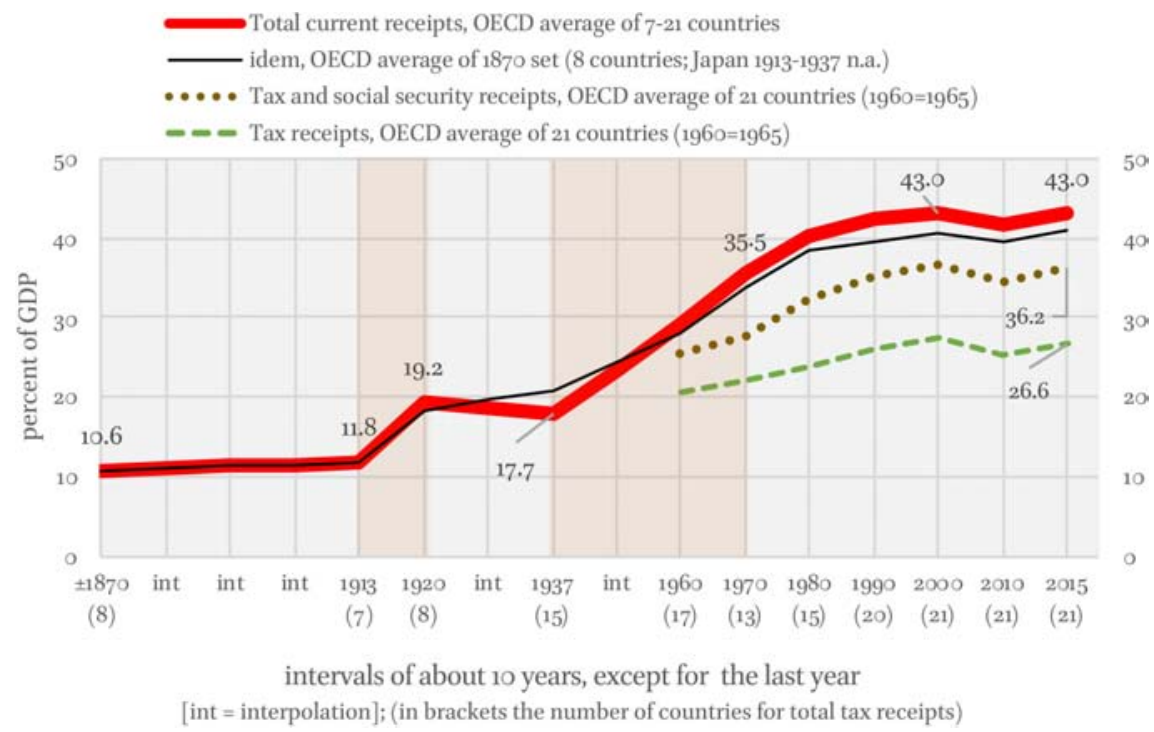

DATA SOURCES: 1870-196o (Tanzi \& Schuknecht 200o); 196o-2015 (oECD data base). For details see Appendix 8.A under 8§4-b

Given that social security expenditures were $10.4 \%$ of GDP in 1960 and $1.7 \%$ in 1930 (Chapter 7, Graph 7.10), it is likely that around 1930 the sum of 'tax and social security receipts' (the middle dotted line in Graph 8.4) nearly coincided with 'tax receipts' (the bottom dotted line).

'Total receipts' includes tax and social security receipts (together the main part) and (chiefly) state receipts from state enterprises (dividends) and from concessions, as well as from retributions, dues and fines (see $8 \S 4-\mathrm{a}$ ).

Graph 8.5 combines Graph 8.2 and Graph 8.4. Hence this graph also shows the budget deficits. (Note that, depending on the rate of growth of GDP, the state's fiscal deficit may but need not result in gross debt increases as a percentage of GDP.) Note again that because these graphs are in terms of GDP shares, cyclical movement is not shown. Moreover, these would anyway be levelled out due to the OECD-21 average and the international non-synchronisation of cycles. Within one country the tax receipts as a percentage of GDP tend to rise in 
upswings and decrease in downswings. Nevertheless, OECD-wide heavy recessions or depressions do show up to some extent in Graph 8.5 in the difference between expenditure and receipts. See the (decade) years 1937 and 2010, and to a lesser extent the 198 os.

GRAPH 8.5 Total state expenditure and total current receipts (general government) 1870-2015, in \% GDP; averages of up to 21 current OECD countries

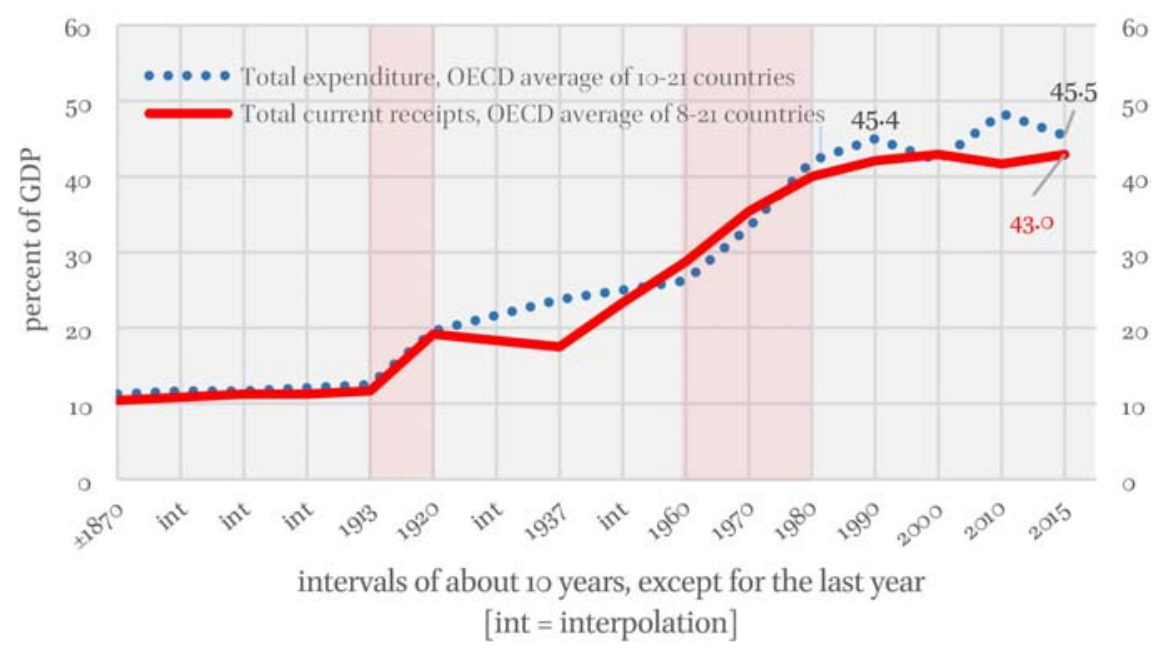

DATA SOURCES: see Graph 8.2 and Graph 8.4

Division 3. The effect of state expenditure on the enterprises' macroeconomic production and validation of surplus-value

After the exposition of state expenditure and finance in general (8D1-8D2), both of the following two divisions present their implications for the enterprise's production and validation of surplus-value (the current division) and for the after-tax surplus-value (8D4). See Scheme 8.1. The current division is the sequel to Chapter 3 's $3 \mathrm{D}_{5}$, 'The validation of macroeconomic surplus-value by macroeconomic expenditure'.

\section{$8 \S 5 \quad$ State expenditure and production of enterprises}

- Recapitulation of state expenditure

Recall from $8 \S 2$ the following definition of state expenditure $(G)$ :

$$
\mathrm{G}=(\mathrm{Wg}+\mathrm{Fg})+\mathrm{Ig}+(\mathrm{Qg}+\mathrm{Zg})
$$

See the left hand side of Table 8.6 for the recapitulation of the categories. 
- Production of enterprises

For their production, enterprises anticipate the validation of production by the expenditure of economic actors ( $3 \S 10$; see also Chapter 5 , Figure 5.2). With the introduction of the state into the systematic exposition, this also applies for the expenditure by or via the state.

TABLE 8.6 Expenditure and current finance account of the state

\begin{tabular}{|c|c|c|c|}
\hline \multicolumn{2}{|l|}{ Expenditure } & \multicolumn{2}{|l|}{ Finance } \\
\hline wages (civil servants) & $\mathrm{Wg}$ & taxes & $\mathrm{T}$ \\
\hline floating inputs (from enterprises) & Fg & social security contributions & SSC \\
\hline $\begin{array}{l}\text { net investment } \\
\quad \text { (fixed inputs from enterprises) }\end{array}$ & Ig & other receipts & OR \\
\hline $\begin{array}{l}\text { interest on state debt } \\
\text { (net payments) }\end{array}$ & Qg & & \\
\hline social security transfers & $\mathrm{Zg}$ & & \\
\hline other expenditure: amenities ${ }^{\dagger}$ & Ag & net current borrowing flow & B \\
\hline Sum of expenditure & $G^{*}$ & Sum of current finance & CFg \\
\hline
\end{tabular}

$\dagger$ Neglected in the current chapter. $G=G^{*}-$ Ag.

$8 \S 5^{-a} \quad$ Explication. Direct and indirect monetary flows from the state to enterprises

Merely for analytical purposes I record that in the absence of savings, all of the expenditures of the state (in whatever way these are financed) end up as sales of enterprises, and so generate income of enterprises. Circuit 8.7 visualises this.

$8 \S 6 \quad$ State expenditure and validation of macroeconomic surplus-value This section shows the effect of state expenditure on the macroeconomic validation of the surplus-value produced in enterprises. For the latter the integrated production and primary income account of enterprises and banks are considered - that is before taxes - recalling that part of the enterprises' 
surplus-value is distributed to banks. (Amplification $8 \S 6$-b outlines a formally more complete presentation of the current section. Instead of going through the rest of $8 \S 6$, the reader might immediately turn to $8 \S 6-b$.)

\section{CIRCUIT 8.7 Destination of state expenditure: purchases}

from enterprises at zero savings

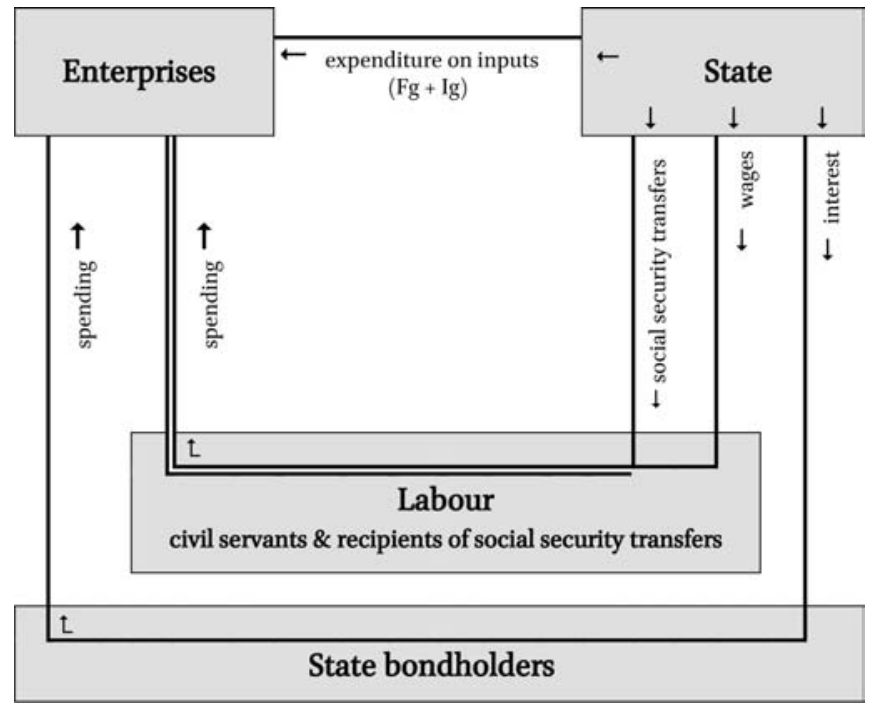

\section{- Recapitulation from Chapter 3}

It was shown in Chapter $3(3 \S 10)$ that given the production of surplus-value $\left(\Pi^{\mathrm{P}}\right)$, the macroeconomic validation of surplus-value $(\Pi)$ is determined, on the one hand, by the investment of enterprises (I) and the consumption expenditure of capital owners (Ck), and, on the other hand, by the (dis)saving by labour, that is, the quantitative difference between their consumption and their wages $(\mathrm{Cw}-\mathrm{W}) .{ }^{11}$ With the introduction of the state and state expenditure, the notation of Chapter 3's enterprises sector is amended by adding extensions ' $\mathrm{e}$ ' (amplified in 8§6-b.) In this amended notation we had:
$\Pi \triangleleft=[\mathrm{Ie}+\mathrm{Ck}]+[\mathrm{Cwe}-\mathrm{We}]$
$\left(3.10^{*}\right)^{12}$
$\Pi \triangleleft=[\mathrm{Ie}+\mathrm{Ck}]-$ Swe

11 Borrowing by labour (which is contingent) is another determinant (Appendix $3 \mathrm{~B}$, section $3^{\mathrm{B}-3)}$.

12 Henceforth an asterisk indicates the changed notation of an earlier equation. Recall that $\varangle$ means that the determination is from the right hand side to the left hand side. 
Thus the validation of surplus-value is positively determined by the net expenditure of enterprises and capital owners $(\mathrm{Ie}+\mathrm{Ck})$ and negatively by the saving of the labour employed by enterprises (Swe).

- Expenditure with enterprises by and via the state

We had for state expenditure $(8 \S 5)$ :

$$
\mathrm{G}=\{\mathrm{Fg}+\mathrm{Ig}\}+\{\mathrm{Wg}+\mathrm{Qg}+\mathrm{Zg}\}
$$

The expenditure on floating inputs $(\mathrm{Fg})$ - the latter inclusive of replacement investment - and on net investment (Ig) directly accrue to the enterprises sector. For the other three categories this is indirectly so via the consumption and depending on the degree of savings - out of these incomes of wages $(\mathrm{Wg})$, interest $(\mathrm{Qg})$ and social security transfers $(\mathrm{Zg})$. For the consumption $(\mathrm{Cxx})$ and savings (Sxx) we have:

$$
\begin{aligned}
& \mathrm{Cwg}=\mathrm{Wg}-\mathrm{Swg} \\
& \mathrm{Cqg}=\mathrm{Qg}-\mathrm{Sqg} \\
& \mathrm{Czg}=\mathrm{Zg}-\mathrm{Szg}
\end{aligned}
$$

These three savings categories together, I call the 'state-mediated savings' (Smg)

$$
\text { Smg }=\text { Swg }+ \text { Sqg }+ \text { Szg }
$$

Focusing on the total of state expenditure $(G)$, it can then be shown (cf. 8§6-b) that

$$
\Pi \triangleleft=[(I e+C k)-S w e]+\mathrm{G}-[\mathrm{Swg}+\mathrm{Sqg}+\mathrm{Szg}]
$$

or

$$
\Pi \triangleleft=[(I e+C k)-S w e]+\mathrm{G}-\mathrm{Smg}
$$

Here the term in square brackets is analogous but quantitatively not the same as equation $\left(3.12^{*}\right)$. This is so because with the state expenditure (minus Smg) the production of enterprises increases. With it at least the investment also increases. To account for the distinction in comparison with Chapter 3 (and all of Part One), the terms $[(I e+C k)-S w e]$ and $\Pi$ are written in italics. (This applies for the rest of the current chapter.)

All of the expenditures and savings in 810 and 8.11 are themselves independent of surplus-value $(\Pi)$ and in that sense autonomous quantities (see $5 \S 3$ and $5 \S 5$ on the autonomy of Ie and $\mathrm{Ck}$ ).

In sum, all of the state expenditure $(G)$ has a positive effect on the surplusvalue produced and validated $(\Pi)$, whereas any saving out of the transfers (Smg) moderates the positive effect. See also Circuit 8.8. (When, in 8D4, I present the effect of taxation on the after-tax surplus-value, the (dis)savings by the state itself will also be accounted for.) 
CIRCUIT 8.8 Destination of state expenditure: purchases and saving

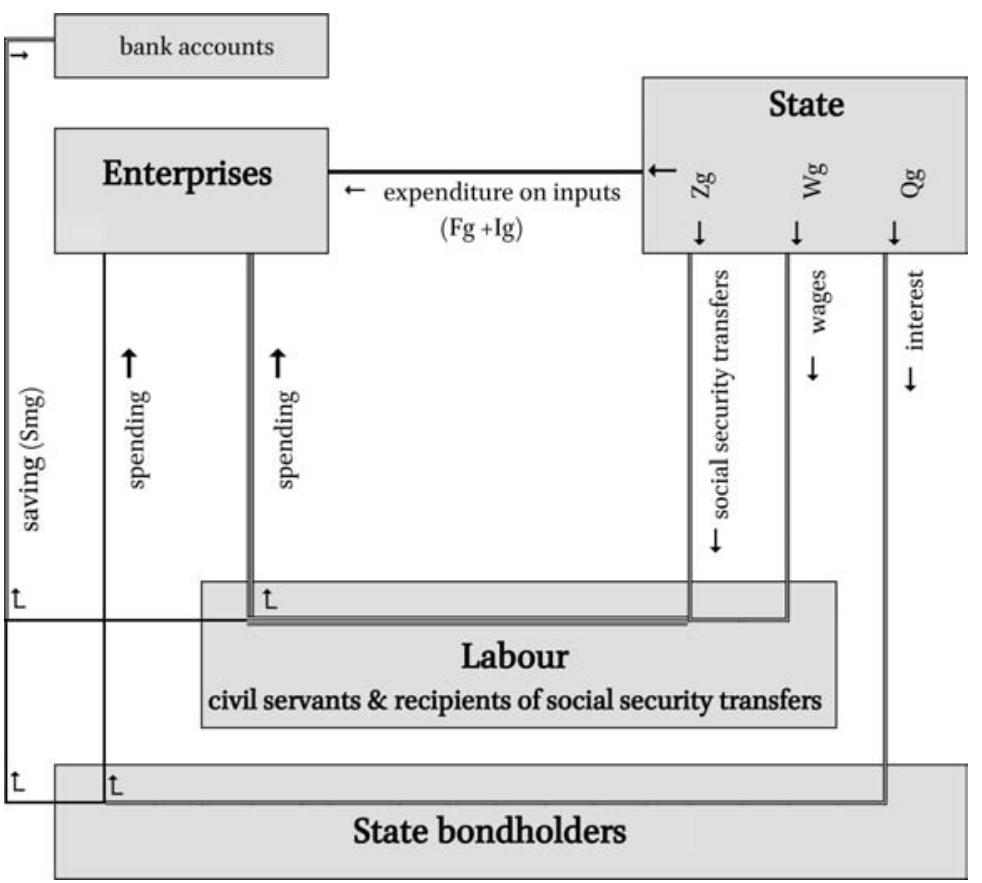

8§6-a Explication. A methodological comment on the production, the validation and the distribution of surplus-value

Onwards from the introduction of capitalist production $\left(\mathrm{iD}_{5}\right)$, a distinction was made between the production of surplus-value and the distribution of surplusvalue. At first this distinction was only implicit $\left(\mathrm{1}_{5}\right)$, but in the course of Chapter 2 and especially Chapter $3\left(3_{1} \mathrm{D}_{-} \mathrm{D}_{3}\right)$ it became explicit, and gradually more detailed (see Figure $3.2 \mathrm{~b}$ ).

With the state's appearance within the exposition (6D2) the activities of the state became explicit. In 8D1 these activities were, economically, conceptualised as production by the state's civil servants. For that production, the state requires inputs from enterprises, and so expends with enterprises. This also is what is made explicit (made explicit, because the capitalist economy can have no existence without the state). In that sense the introduction of the state into the exposition does not give rise to extra production by enterprises. Nevertheless it is the case that an impetus to extra expenditure by the state does give rise to extra production of enterprises - and hence (ceteris paribus) of production of extra surplus-value. 
Only in the next division (8D5), which expands on taxation, will it become explicit that, via the taxation of enterprises, the distribution of surplus-value is also affected.

8§6-b Amplification. The effect of state expenditure on the (before tax) macroeconomic validation of surplus-value - a formal derivation

Here the macroeconomic validation of production through expenditure is considered and therewith the generation of primary income: surplus-value and wages. Only after that is the secondary distribution of income considered: especially the distribution of surplus-value as including taxation (the latter in $8 \mathrm{D}_{4}$ ). Two distinct macroeconomic sectors are treated: the enterprises sector (the integration of enterprises and the non-lending and borrowing part of banks) with symbol 'e', and the state sector (with symbol ' $\mathrm{g}$ ').

Equation numbers refer to those of the main sections (equations 8.1-8.11). Equations added in this amplification are numbered 8.6b.1, 8.6b.2, etc. (6b refers to the current amplification, and the last digit to the equation added).

1 Reconceptualisation of the domain: some minor changes in notation With the incorporation of the state into the systematic exposition, we have formally a domain extension. In order to keep the formal presentation transparent and concise, I redefine the notation of $3 \S 10$, now introducing extensions ' $\mathrm{e}$ ' for the enterprises sector and extensions ' $\mathrm{g}$ ' for the state ( $\mathrm{g}$ for government)see Table 8.9. I could have introduced this notation in Chapter 3, but I did not want to anticipate Chapter 8 too much.

TABLE 8.9 Notation for the formal domains of Chapters 3 and 8

\begin{tabular}{|c|c|c|c|c|}
\hline & \multicolumn{2}{|c|}{ Enterprises sector } & \multirow{2}{*}{\multicolumn{2}{|c|}{$\begin{array}{l}\text { Formal domain } \\
\text { extension Ch. } 8\end{array}$}} \\
\hline & notation $3 \S 10$ & notation Ch. 8 & & \\
\hline value-added (net) & $\mathrm{Y}$ & $Y e$ & $Y$ & $=Y e+Y g$ \\
\hline investment (net) & I & $I e$ & $\mathrm{I}$ & $=I e+\operatorname{Ig}$ \\
\hline wages (sum) & $\mathrm{W}$ & $W e$ & $\mathrm{~W}$ & $=W e+W g$ \\
\hline consumption out of wages & $\mathrm{Cw}$ & Cwe & $\mathrm{Cw}$ & $=C w e+\mathrm{Cwg}$ \\
\hline saving out of wages & Sw & Swe & Sw & $=S w e+$ Swg \\
\hline
\end{tabular}

Because the state produces no surplus-value and capital, I keep for the consumption by capital owners: $\mathrm{Ck}=\mathrm{Ck}$. Because surplus-value is produced only in enterprises $(\Pi \equiv \Pi$ ) I keep $\Pi$, but write this in italics $(\Pi)$, so as to make 
explicit that, as we will see, the introduction of the state formally implies an expansion of surplus-value. Along with it the other Chapter 3 components are put in italics (Table 8.9, column 4).

Above and below all the time indices are omitted (implicitly these are all ' $t$ '). In this new notation I recapitulate two main equations from Chapter 3 :

$$
\begin{aligned}
& \Pi \varangle=\mathrm{Ie}+\mathrm{Ck}+(\text { Cwe-We }) \\
& \Pi \varangle=\mathrm{Ie}+\mathrm{Ck}-\text { Swe }
\end{aligned}
$$

(Henceforth an asterisk indicates the changed notation of an earlier equation.) sectors

I adopt a macroeconomic two-sector approach in which the enterprises sector and the state are not being integrated (hence a separate, though interconnected, Ye and Yg).

$$
Y=Y e+Y g
$$

(where $Y$ in italics is total net value-added when the state is explicit).

$2 a$

$$
\text { The state (and state-mediated) sector }
$$

$\mathrm{Yg}=\mathrm{Wg}$

We have for state expenditure $(8 \S 2)::^{13}$

$$
\mathrm{G}=\{\mathrm{Fg}+\mathrm{Ig}\}+\{\mathrm{Wg}+\mathrm{Qg}+\mathrm{Zg}\}
$$

The expenditure on floating inputs inclusive replacement investment $(\mathrm{Fg})$ and net investment (Ig) directly accrues to the enterprises sector. For the other three categories this is indirectly so via consumption, and depending on the degree of savings out of these incomes of wages $(\mathrm{Wg})$, interest $(\mathrm{Qg})$, and social security transfers $(\mathrm{Zg})$. For the consumption $(\mathrm{Cxx})$ and savings $(\mathrm{Sxx})$ we have:

$$
\begin{aligned}
& \mathrm{Cwg}=\mathrm{Wg}-\mathrm{Swg} \\
& \mathrm{Cqg}=\mathrm{Qg}-\mathrm{Sqg} \\
& \mathrm{Czg}=\mathrm{Zg}-\mathrm{Szg}
\end{aligned}
$$

These three savings categories together I call the 'state-mediated savings' (Smg)

$$
\text { Smg }=\text { Swg }+ \text { Sqg }+ \text { Szg }
$$

$2 b$

\section{The enterprises sector}

From the side of the realised net production of the enterprises sector we have the value-added of:

$$
Y e \triangleleft=\left[m L^{\alpha}\right]
$$

\footnotetext{
13 Here the pure case is considered in which the state does not own enterprises that sell. If it does, then these are subsumed under enterprises, the state receiving dividends.
} 
where $m$ is the realisation constraint resulting in the unit monetary value of labour.

$$
\begin{aligned}
& Y e=W e+\Pi \\
& \Pi=Y e-W e
\end{aligned}
$$

From the side of expenditure we have the following three equations.

For the final expenditure of the non-state sector with the enterprises sector (Ee):

$$
E e=I e+C k+C w e
$$

For the direct and indirect spending of the state sector with the enterprises sector $(\mathrm{Eg})$ :

$$
\mathrm{Eg}=[\mathrm{Ig}+\mathrm{Fg}]+[(\mathrm{Cwg}+\mathrm{Cqg}+\mathrm{Czg})]
$$

Taking the last two equations together we have the determination of:

$$
Y e \triangleleft=E e+E g
$$

The macroeconomic surplus-value is the sum of these expenditures minus the wages of the enterprises sector:

$$
\Pi \triangleleft=(E e+\mathrm{Eg})-W e
$$

Substituting (3.6 $\left.6^{* *}\right)$ and (8.6b.2), into (8.6b.4) we have:

$$
\Pi \triangleleft=[(I e+C k)+(C w e-W e)]+[\mathrm{Ig}+\mathrm{Fg}]+[(\mathrm{Cwg}+\mathrm{Cqg}+\mathrm{Czg})]
$$

where the shaded part is analogous to equation $\left(3.10^{*}\right)$ above.

Substituting 8.6, 8.7. and 8.8 we get:

$$
\begin{aligned}
\Pi \triangleleft= & {[(\mathrm{Ie}+\mathrm{Ck})+(C w e-W e)]+[\mathrm{Ig}+\mathrm{Fg}+\mathrm{Wg}+\mathrm{Qg}+\mathrm{Zg}]-} \\
& {[\mathrm{Swg}+\mathrm{Sqg}+\mathrm{Szg}] }
\end{aligned}
$$

Here the second term on the right hand side is the state expenditure (equation 8.3 above). When substituting this we get:

$$
\begin{aligned}
\Pi \triangleleft & =[(I e+C k)+(C w e-W e)]+\mathrm{G}-[\mathrm{Swg}+\mathrm{Sqg}+\mathrm{Szg}] \\
\Pi \ll & =[(I e+C k)-\text { Swe }]+\mathrm{G}-\mathrm{Smg}
\end{aligned}
$$

These expenditures and savings are themselves independent of surplus-value $(\Pi)$ and in that sense autonomous quantities (see $5 \S 3$ and $5 \S 5$ on the autonomy of Ie and $\mathrm{Ck}$ ).

Thus the validation of surplus-value $(\Pi)$ depends positively on the final expenditure by the enterprises sector and by capital owners $(\mathrm{Ie}+\mathrm{Ck})$ as well as on the state expenditure $(G)$, and negatively on the saving out of enterprises wages (Swe) and out of the state-mediated saving (Smg).

This is most transparent for the case in which there would be no savings (that is, for $C w e=W e$ and $\mathrm{Smg}=0$, whence we would have $\Pi^{*}=I e+C k+\mathrm{G}$ ). Paraphrasing Kalecki, we then have: capitalists earn what they spend and what the state directly and indirectly spends.

Recall that enterprises cannot determine the validation of their surplusvalue $(3 \S 10)$. Given the production of surplus-value - that each individual 
enterprise can control separately - the macro validation of surplus-value $(\Pi)$ is determined by the expenditure components above (8.6b.5 and the derived 8.11), which the individual enterprises cannot control, even if they can control their own individual investment expenditure. ${ }^{14}$

8§6-c Amplification. From surplus-value to the before tax internal profit of enterprises

Having outlined the validation of surplus-value in $8 \S 6$ and $8 \S 6$-b, we can now turn to the first stage of the distribution of surplus-value (prior to taxation). This regards the distribution of surplus-value $(\Pi)$ as interest, whence we move from $\Pi$ to the internal profit of the enterprises sector ( $R$, now in italics). (At the level of Chapter 3 , the internal profit of enterprises was introduced briefly $3 \S 1$, cf. Figure $3.2 \mathrm{~b}$, and more extended in Chapter $5,5 \S 1$.)

Given the determination of surplus-value validated,

$$
\Pi \triangleleft=[(I e+C k)-S w e]+\mathrm{G}-\text { Smg }
$$

we have for the internal profit of the enterprises sector:

$$
R=\Pi-\mathrm{Qe} \quad\{\text { for net interest payments } \mathrm{Qe}>0 \text { \} (8.6c.1) }
$$
where Qe is the net interest paid by enterprises to their external financiers. ${ }^{15}$

Hence we have for the enterprises' internal profit:

$$
R=[(I e+C k)-S w e]-[\mathrm{Qe}]+[\mathrm{G}-\mathrm{Smg}]
$$

8§6-d Addendum. A comment on the System of National Accounts (SNA 2008)

The ordering of categories above can be connected to that of the System of National Accounts 2008 (SNA 2008; see UN 2009), which, in general terms, roughly adopts the same order regarding the generation of income versus its distribution. This, however, does not imply that I would agree with all of the SNA's ordering decisions; especially I disagree with almost all of its ordering when this requires an 'imputation' of one economic category to another. (I especially distance myself from the imputation of owner-occupied dwellings to a nominal entrepreneurial branch - from which the owner is a nominal tenant - the branch securing an operating surplus via the imputed rentals (see the very last section of Appendix ${ }_{3} \mathrm{C}$ ). I also especially take distance from the way

\footnotetext{
14 This is a Kaleckian argument.

15 Recall that for the latter we had in equation 5.1 of $5 \S 1$ the notation $i \varepsilon \mathrm{K}$. This is also adequate at the current point. The notation Qe merely serves to make the reader aware that 'net' interest now may be net of also interest payments to enterprises from the state.
} 
the value-added of banks is accounted for, that is, via the imputation of intermediate uses (bank services) to interest receipts and payments of banks.) ${ }^{16}$

Apart from these imputations my ordering is different from the SNA's in that I consistently treat all taxation (the direct on incomes and the indirect on products) at one and the same level. A rather minor point is that I treat net rather than gross investment (the SNA accounts allow for each one).

Quite a different point is that (at the current general level of exposition) international relations are yet abstracted from. Together this means that - in SNA terminology - I start from macroeconomic production and the realisation of macroeconomic production at the level of 'net value-added' or the 'net domestic product against factor costs', with all international related items put to zero.

\section{Division 4. The combined effect of state expenditure and taxation on the enterprises' macroeconomic after-tax surplus-value}

This division presents, first, the combined effect of state expenditure $\left(8 \mathrm{D}_{3}\right)$ and of taxation of enterprises on the latter's after-tax surplus-value $(8 \S 7)$. Next it presents, more specifically, the effect of a fiscal deficit of the state on the enterprises' after-tax surplus-value ( $8 \S 8)$.

\section{$8 \$ 7 \quad$ A profits tax: taxation of surplus-value}

- Finance and pre-finance of state expenditure

Enterprises usually pay taxes after having realised the surplus-value to pay these. This may seem an obvious statement. Behind it, however, is the perhaps less obvious fact that - depending on savings and other taxes - the state expenditure $(G)$ largely generates the before tax surplus-value equivalent for the enterprises taxes. The state makes the required expenditure and, given the going tax rates, it must await how much tax revenue the two generate (this is how the state makes its budget and carries it out; it may estimate the tax collection, but the outcome is uncertain). Pending this tax collection, the state must (pre-)finance its expenditure via borrowing (directly through banks or indirectly via the issue of short-term bonds or treasury bills).

16 Even if for the SNA 2008 (UN 2009) the composers may have made a number of arbitrary choices, it seems by and large an impressively consistent and precise whole (of over 6oo pages). The sequel representing the accounts in excel (UN 2008a) is a useful leading summary even if that is a summary consisting of many thousands of entries. 


\section{- The effect of a tax on surplus-value}

Total taxes (T) are made up of the 'taxes on surplus-value realised' (Tsv) and all other taxes (To). The latter (To) are specified in $8 \mathrm{D}_{5}$.

$$
\mathrm{T}=\mathrm{Tsv}+\mathrm{To}
$$

The before $(\Pi)$ and the after-tax surplus-value ( $\Pi$ at) are related as:

$$
\Pi \text { at }=\Pi-\mathrm{Tsv}
$$

Recall from $8 \S 6$ the equation for the realisation of surplus-value $(\Pi)$ :

$$
\Pi \triangleleft=[(I e+C k)-S w e]+\mathrm{G}-\mathrm{Smg}
$$

(with Swe for the saving out of enterprises wages and Smg for the saving out of the state-mediated spending).

Substituting the last equation into the former we get:

$$
\Pi \text { at }=[(I e+C k)-S w e]+[\mathrm{G}-\mathrm{Smg}-\mathrm{Tsv}]
$$

Consider the second term in square brackets $[\mathrm{G}-\mathrm{Smg}-\mathrm{Tsv}]$.

First. The taxes (Tsv) are the costs for enterprises of the state's actualisation in terms of production and expenditure $(8 \mathrm{D} 1)$ of the seven legislative frameworks (Chapters $6-7$ ). Regarding the latter, specifically the state's upholding of the granted legal economic rights for enterprises (Chapter 6).

Secondly, however, these costs (Tsv) go along with benefits in the form of state expenditure on the frameworks, benefits that directly or indirectly expand the output of enterprises ( $\mathrm{G}-\mathrm{Smg}$ ), and so their surplus-value.

Given the state and its actualised accommodation of the production of surplus-value, the effect of this $\operatorname{tax}$ (Tsv) is that part of the pre-tax surplus-value is distributed to the state (see Figure 8.10).

Recalling that the savings of the enterprises' labour are the difference between their wages and consumption (Swe $=\mathrm{We}-\mathrm{Cwe}$ ) we can also write (8.14) as

$$
\Pi \text { at }=[(I e+C k)+C w e-W e]+[\mathrm{G}-\mathrm{Smg}-\mathrm{Tsv}]
$$

In sum, therefore, we see that whereas each of the enterprises' wages (We) and taxes (Tsv) are costs for the generation of surplus-value, labour and the state also generate expenditure benefits ( $\mathrm{Cw}$ and $\mathrm{G}-\mathrm{Smg}$ ).

A corollary of this tax is that 'the tendency to equalisation of average intersector rates of integral profit' $(4 \S 2)$ takes the form of 'the tendency to equalisation of average inter-sector after-tax rates of integral profit'.

The figure on the next page is a completed version of Figure $3.2 \mathrm{~b}(3 \S 1)$.

8§7-a Amplification. The effect of a tax on the profit of enterprises The main text presented the taxation of surplus-value $(\Pi)$. Contingently the state may allow enterprises to deduce interest payments (that is, this distribution of surplus-value) from the surplus-value tax, whence we have in fact a tax on internal profit. 
FIGURE 8.10 The distribution of surplus-value to financiers and to the state

validated production

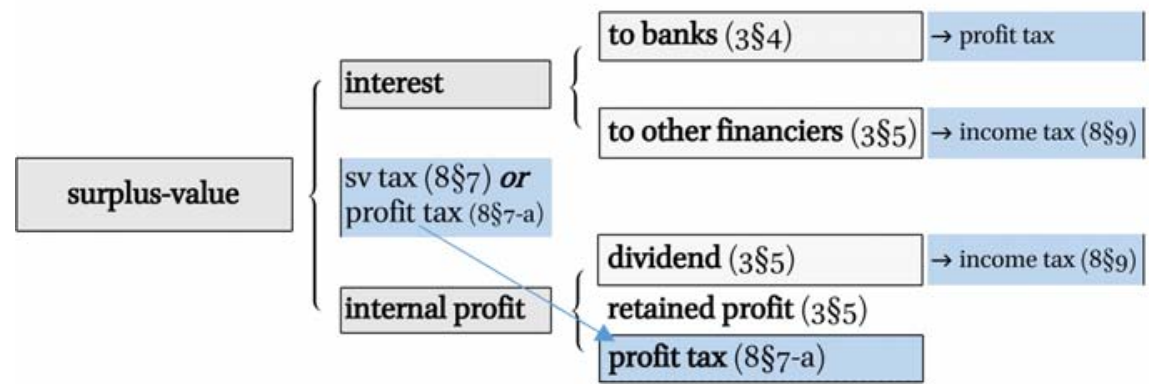

Following on from an earlier amplification on the internal profit of enterprises (8§6-c) the current amplification considers a tax on the internal profit $(R)$, that is, $\Pi$ after the distribution of interest (thus we now have a smaller tax base). Recall from $8 \S 6-\mathrm{c}$ :

$$
\begin{aligned}
& R=\Pi-\mathrm{Qe} \quad\{\text { for net interest payments Qe }>0\} \\
& R=[(I e+C k)-S w e]-[\mathrm{Qe}]+[\mathrm{G}-\mathrm{Smg}]
\end{aligned}
$$

Total taxes $(\mathrm{T})$ are made up of the taxes on the internal profit of enterprises $(\mathrm{Tr})$ and other taxes $\left(\mathrm{To}^{*}\right)$.

$$
\mathrm{T}=\mathrm{Tr}+\mathrm{To}^{*}
$$

The after-tax internal profit (Rat) is defined as:

$$
\text { Rat }=R-\operatorname{Tr}
$$

Substituting (8.6d.2) into the last equation we have:

$$
R a t=[(I e+C k)-S w e]-[\mathrm{Qe}]+[(\mathrm{G}-\mathrm{Smg})-\mathrm{Tr}]
$$

The last term in square brackets represents the benefits (G-Smg) and costs (Tr) that the enterprises sector derives from the state, for the former's accommodation of the generation of the profits of enterprises.

A corollary of this tax is that 'the tendency to equalisation of average intersector rates of internal profit' ( $5 \S 1$ ) takes the form of 'the tendency to equalisation of average inter-sector after-tax rates of internal profit'.

The information provided by equation (8.7a.3) is not much different from that of the last but one in the main text of $8 \S 7$ :

$$
\Pi \text { at }=[(I e+C k)-S w e]+[\mathrm{G}-\mathrm{Smg}-\mathrm{Tsv}]
$$

$8 \S 8 \quad$ The effect of a fiscal deficit of the state on the after-tax surplus-value Although the state's fiscal stance (surplus or deficit) is contingent, the state tends to run structurally a fiscal deficit. (See, for example, the earlier Graph 8.5, in $8 \S 4$-b, for the OECD-21 between 1870 and 2015 . Given the available data it 
seems that the period of fiscal surpluses between just before 1960 and just after 1970 is exceptional.) It is therefore relevant to consider the effect of a (structural) fiscal deficit, on the after-tax surplus-value of enterprises, which is the subject of the current section. We get to this in subsection (3) below. Subsection (1) serves to simplify the notation. Subsection (2) introduces the concept of saving by the state.

\section{Hybrid taxes}

A fiscal surplus of the state is equivalent to the state's 'saving', and a fiscal deficit to its 'dissaving'. This is not simply the difference between its expenditure $(G)$ and taxes $(G)$, because the state has also other incomes.

Recall from $8 \S 4$ the equation for the 'current finance of expenditure' ( $\mathrm{CFg}$ ).

$$
\mathrm{CFg}=\mathrm{T}+\mathrm{SSC}+\mathrm{OR}+\mathrm{B}
$$

( $\mathrm{T}$ for taxes, ssC for social security contributions, OR for other receipts and B for the net current borrowing flow.)

Recall from $8 \S 7$ the equation of taxes (with To for 'other taxes'):

$$
\mathrm{T}=\mathrm{Tsv}+\mathrm{To}
$$

Substituting (8.12) into (8.4) we have:

$$
\mathrm{CFg}=\mathrm{Tsv}+\mathrm{To}+\mathrm{SSC}+\mathrm{OR}+\mathrm{B}
$$

In order to simplify the notation below, I introduce the term 'hybrid taxes' $\left(\mathrm{T}^{\mathrm{H}}\right)$, defined as:

$$
\mathrm{T}^{\mathrm{H}}=\mathrm{Tsv}+\mathrm{To}+\mathrm{SSC}+\mathrm{OR}
$$

The last three terms are taken together as 'other hybrid taxes' $\left(\mathrm{T}^{\mathrm{H}} \mathrm{O}\right)$.

$$
\mathrm{T}^{\mathrm{H}}=\mathrm{Tsv}+\mathrm{T}^{\mathrm{H}} \mathbf{O}
$$

2

\section{Saving by the state, or a fiscal deficit as reflected in dissaving}

Substituting (8.12) and (8.15) into (8.4) we have

$$
\mathrm{CFg}=\mathrm{T}^{\mathrm{H}}+\mathrm{B}
$$

In case of a fiscal surplus, $B$ is negative (thus the state pays off part of its debt).

Recall that the sum of state expenditure $(G)$ equals its current finance.

$\mathrm{CFg}=\mathrm{G}$

The current savings of the state $(\mathrm{Sg})$ are defined as

$$
\mathrm{Sg}=\mathrm{T}^{\mathrm{H}}-\mathrm{G}
$$

Or: $\mathrm{G}-\mathrm{T}^{\mathrm{H}}=-$ Sg. For a fiscal deficit (thus $\mathrm{G}>\mathrm{T}^{\mathrm{H}}$ and $\mathrm{B}>0$ ) the saving $\mathrm{Sg}$ is negative (thus we have dissaving by the state).

3 The effect of a fiscal deficit on the after-tax surplus-value In the previous section $(8 \S 7)$ we had for the after-tax surplus-value:

$$
\Pi \text { at }=[(I e+C k)-S w e]+[\mathrm{G}-\mathrm{Smg}-\mathrm{Tsv}]
$$

By substituting (8.16) into (8.14) we make explicit both the taxation stance of 
the state $(\mathrm{G}-\mathrm{T})$ and the sum of the 'other hybrid taxes' $\left(\mathrm{T}^{\mathrm{H}}\right)$, as each determining the after-tax surplus-value of the enterprises sector.

$$
\Pi \text { at }=[(I e+C k)-S w e]+\left[\left(\mathrm{G}-\mathrm{T}^{\mathrm{H}}\right)-\mathrm{Smg}+\mathrm{T}^{\mathrm{H}} \mathrm{O}\right]
$$

Thus to the extent that the state acts such that the appropriators of surplusvalue 'share' the total burden of the hybrid taxation with other payers of hybrid taxes $\left(\mathrm{T}^{\mathrm{H}} \mathrm{O}\right)$, the after-tax surplus-value is larger - that is, given the other components.

By substituting (8.18) into (8.19), the (dis)savings of the state are made explicit (its fiscal surplus or deficit) as

$$
\text { Пat }=[(I e+C k)-S w e]+\left[-\mathrm{Sg}-\mathrm{Smg}+\mathrm{T}^{\mathrm{H}} \mathrm{O}\right]
$$

Thus the after-tax surplus-value is negatively affected by a fiscal surplus $(\mathrm{Sg}>0) .{ }^{17}$ Conversely, a fiscal deficit ( $\mathrm{Sg}<0$, hence $-\mathrm{Sg}>0$ ) has a positive effect on the after-tax surplus-value.

However, although the statement in the last sentence is formally correct, the total of the state debt - and the interest payments along with it - has a secondary effect on the savings by the state bondholders. (Recall from equation 8.9, in $8 \S 6$, that this saving, Sqg, is part of the 'state-mediated savings' Smg.) To the extent that the total state debt would keep increasing (say, as a percentage of GDP) then at some point the savings effect of bondholders (Sqg) is going to outrun the budget deficit effect (Sg). ${ }^{18}$ (In considering this, it should be kept in mind that as long as the state's budget deficit as a percentage of GDP, e.g. $2 \%$, is smaller than the rate of growth of GDP, e.g. $2.5 \%$, then the total state debt as a percent of GDP decreases.)

8§8-a Addendum: Kalecki on the state budget deficit and profits The idea that the budget deficit of the state positively affects profits stems from Kalecki (see, e.g., his 2003 [1954], pp. 48-9), although he does not go into sim-

17 The form of equation (8.20) is in essence no different from the result reached in $3 \S 10$ (equation 3.12). This is transparent for the case in which all taxation would be levied on the enterprises sector $\left(\mathrm{T}^{\mathrm{H}} \mathrm{O}=0\right)$. Thus profits are positively determined by the final expenditures of enterprises (Ie) and of capital owners ( $\mathrm{Ck}$ ), and negatively by the savings of all other actors (now including the state). Recall that the exposition in this book takes distance from the orthodox view of investment being a saving $(3 \S 9)$.

18 On the basis of twentieth-century data for the average of the OECD-21 of before and after the early twentieth-century financial crisis on the one hand, and a number of plausible savings assumptions on the other, it can be inferred that this 'outrunning' does not occur for state debts below $100 \%$ of GDP. However, this would far from imply that the term [$\mathrm{Sg}-\mathrm{Smg}+\mathrm{T}^{\mathrm{H}} \mathrm{O}$ ] in equation 8.20 would become negative. For the OECD-21, and at least over the last $5 \mathrm{O}$ years, the $\mathrm{T}^{\mathrm{H}} \mathrm{O}$ has kept increasing from $28.2 \%$ of GDP in 1979 to $32.2 \%$ in 2015. (Taxes on profits of corporate enterprises in terms of GDP changed from $2.3 \%$ in 1970 , via $3.7 \%$ in 2000 , to $2.9 \%$ in 2015 .) 
ilar detail as in the main section. Minsky remarks: 'Ever since the early work of Kalecki it has been known that gross profits equals gross investment plus the government deficit .... And: 'Although sustaining and increasing business profits has never been an avowed objective of active fiscal policy - employment or income have been the avowed policy objectives - a major effect of the big deficits that big governments generate when income falls is to sustain profits' (Minsky 1982, pp. 389 and 388).

\section{Division 5. Forms of taxation: the distribution of income and wealth}

The previous division presented the effect of taxation on the after-tax surplusvalue. In principle the state might levy all the required taxes on surplus-value. Given that the state acts such that enterprises 'share' taxation with households, this final division presents the effect of the particular actual form of taxation on the distribution of the income of households $(8 \S 11)$, and on the distribution of the wealth of households $(8 \S 12)$. These sections are preceded by some categorising outlines $(8 \S 9-8 \S 10)$.

A methodological remark is appropriate at this point. Whereas taxation is necessary, the specific forms of taxation are contingent. Their outcome in the distributions of income and wealth are in fact a 'manifestation' of the capitalist system (presented in Chapters 4-5 and 9-10). However, as these distributions relate qua theme to the current chapter, I have included it here, at the end of this chapter.

\section{$8 \$ 9$ The finance of social security: taxes and social security contributions}

In ${ }_{7} \mathrm{D}_{5}$ the framework of legitimating social security provisions (or 'transfers') was presented in general terms. Recall the transfer categories presented in Figure 7.8 and Graph $7.9(7 \S 17)$.

Social security provisions are financed in two ways. Mostly one part is financed out of taxation and the other part out of social security contributions (ssc), which are most often in part paid by employers and in part by workers.

ssc-related provisions are considered to have a collective insurance character and to be work-related (e.g. non-structural unemployment, sickness pay, and wage-related pensions). In a way these are not 'pure' social transfers, but rather a collective insurance for which only those who work are eligible, and only those who worked can receive benefits. Regarding wage-related pension benefits in particular, it is to be mentioned that these are either the result 
of a formal insurance, or have the character of a postponed wage. (Recalling that for the OECD-21, in 2010, pensions constitute about one-third of the social security transfers - see Graph 7.9 - it is indeed dubious whether the wage-related, or premium-related, part of these should be classified as 'social' transfers.)

This is thus different from transfers that are not work related, such as fixed amount (equal for all) state pensions that are financed out of taxation, as well as child and other allowances, social assistance, and state serviced (contributions to) health provisions - all these are most often financed by taxation.

Social security contributions paid by workers are inevitably paid out of their gross wage. However, employers SSC are also part of the gross wage. (This is also how the System of National Accounts, SNA 2008 accounts for these. $)^{19}$ For the employer these are 'wage costs'.

The distribution of the ssc between employers and workers is contingent on wage bargaining, and in several countries contingent on economic policy decisions. However, to a large extent the outcome is merely an 'optical' matter of take home pay (to the extent that the workers ssc part is larger, the gross wage paid can be larger). What does matter, though, for the distribution of income is any wage bargaining or economic policy decisions that either set an upper threshold for Ssc (making the distribution of income more skewed) or that set an upper threshold on the transfers/benefits (making the distribution of income less skewed) - in each case given the total wages sum that employers are willing to pay.

It is contingent (and country dependent) if, and which, social transfers are taxed.

8§9-a Amplification. The finance of social security in the OECD-21: 1970-2015

Graph 8.11 shows how social security in the OECD-21 is financed on average. There is quite some variation among these countries. For example, in Australia and New Zealand $100 \%$ is financed out of taxation and in Denmark nearly $100 \%$, whereas in France, Germany, Japan, and the Netherlands over $50 \%$ is financed out of ssc (year 2010).

From the point of view of social security contributions (SSC) and for the OECD-21 on average, about one-third of the social security transfers (SST) are in fact a wages component - one that may or may not be taxed - as shown in Table 8.12.

19 SNA 2008 (UN 2009), chapter 7 B, Compensation of employees, in particular Table 7.4 and the text on pp. 138-9. See also OECD 2013. 
GRAPH 8.11 Finance of social security provisions 1970-2015, shares of social security contributions (SSC) and taxes; averages of $O E C D-21$

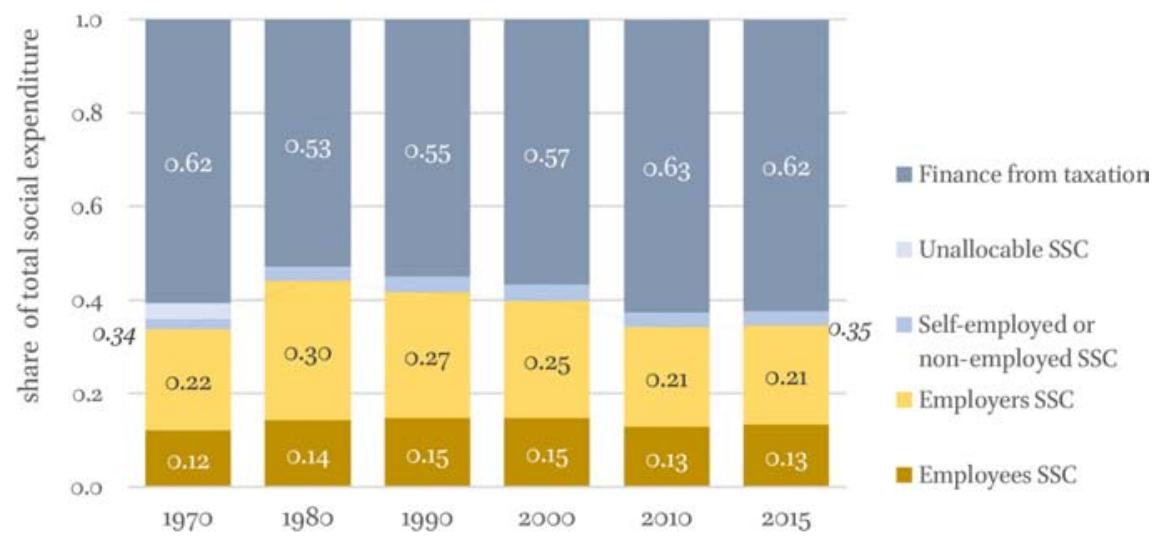

DATA SOURCES: Social security contributions (ssC) (OECD dataset Revenue Statistics - Comparative tables, series 2100, 2200, 2300 and 2400); ${ }^{20}$ Social security expenditure (see Graph 7.10)

TABLE 8.12 Finance of social security, and social security contributions as part of the gross wage

\begin{tabular}{llll}
\hline & Employers & Workers & State \\
\hline finance of social security & $\mathrm{x} \%$ & $\mathrm{y} \%$ & $(1-\mathrm{x}-\mathrm{y})$ \\
& contributions & contributions & out of taxation \\
$\begin{array}{c}\text { component of the 'gross wage' } \\
\quad \text { (regarding previous row) }{ }^{\dagger}\end{array}$ & yes (wage costs) $)^{\ddagger}$ & yes & no \\
taxation of social sec. transfers & n.a. & varies between countries & \\
& & for different transfers & \\
\hline
\end{tabular}

$\dagger$ This is also how the System of National Accounts 2008 (SNA 2008) conceptualises this matter (see the previous footnote).

‡ This is also the difference between the concept of 'wages' and 'wage costs'. These contributions are directly paid to the institution administering the social security - hence workers do not receive this in cash, although it is theirs (the same applies most often for the next column).

20 http://stats.oecd.org/OECDStat_Metadata/ShowMetadata.ashx?Dataset= REV\&ShowOnWeb=true\&Lang=en (last updated August 2017; accessed 28 December 2017). 


\section{$8 \S 10$ Forms of taxation}

Recall from $8 \S 5$ 's Table 8.6 (and Graph 8.4 in $8 \S 4$ ) the forms of finance of the state. Given that there are limits to contingent borrowing and to other non-tax incomes of the state, taxation is the main and necessary form of finance of the state $(8 \S 4)$. However, the particular form of taxation is contingent. The 'pure' form of taxation would be taxes on the enterprises' property and surplus-value, that is, when taxation would be connected to the initial ground of the state (6§1 and 6§11). In actual practice labour 'shares' in the taxes, regarding both their labour income and their spending. Hence there are four main categories of taxation: ${ }^{21}$

1. Taxes on profits

- taxes on corporate profits (legal corporations);

- taxes on other profits (non-incorporated firms);

2. Taxes on property value and property income

- property value taxes (taxes on wealth);

- property income taxes (taxes on distributed interest and on dividends and rent);

- taxes on the succession of property;

3. Taxes on labour income and its derivatives

- labour income taxes;

- taxes on social security transfers; ${ }^{22}$

- taxes on benefits from pension funds (cf. Chapter 3, Appendix 3A-2);

4. Taxes on products (indirect taxes)

- taxes on the value of products (at production, sale or transfer; or at final use); these include the indirect value-added tax (VAT); ${ }^{23}$

- taxes per unit of goods or services (excise).

In case all these four forms prevail, all classes of actors are subject to levies of the last category and, depending on their roles, they might fall into one or all of the first three categories.

The state can - up to its discretion in face of its legitimation requirement in principle choose between degrees of these various forms of taxation.

21 Precise definitions can be found in the SNA 2008 (UN 2009).

22 Among current OECD countries there is quite some diversity as to their taxation. See Adema, Fron and Ladaique 2011.

23 Collected in stages by enterprises; ultimately charged in full to the final purchases. 


\section{$8 \S 11$ Forms and design of taxation, and their legitimation in compliance to a particular distribution of income}

As with all main state actions, the form and the specific design of taxes must ultimately be legitimated in the compliance of actors. In the end this concerns the compliance to a particular distribution of income and wealth via taxation. The current section focuses on the distribution of income and the next one on the distribution of wealth.

\section{Taxation inevitably takes a stance}

I make a distinction between the forms of taxation (the categories outlined in $8 \S 10$ ) and their design (tax rates and the tax base for these rates). There cannot be 'neutral' taxes or neutral tax rates. More specifically regarding tax rates, flat rates are no more neutral than progressive or regressive ones. Propagating flat rates would seemingly imply a normative judgement regarding the outcome of 'the market' and the resulting distribution of income and wealth before taxation. However - and quite apart from the moral or ethical norm - such a judgement is based on the illusion that 'the market' could exist at all, and specifically so independently of the state and its expenditure. Independently of judgements about the form and the design of taxes, 'the market' is a phantom to the extent that it has no existence without the rights frameworks and the economic frameworks presented in Chapters $6-7 \cdot{ }^{24}$ Moreover, because the state exists, 'markets in a vacuum of non-taxation' do not exist. There can be tax shifts, though no tax shift can be actualised in a vacuum of non-taxation. In sum, any actual form and design of taxation is inevitably based on a normative stance of the state, and only shifts in taxation and/or their design can be identified as being redistributive.

2

\section{Tax rates}

The particular form of taxation being contingent, at least one form must necessarily be implemented. The same applies for their design: there must necessarily be some tax rate (regressive, flat or progressive) that affects the distribution of income or wealth. An important difference between the four main forms of taxation $(8 \S 10)$ concerns their potential for changes in the distribution of income and wealth via progressive, flat or regressive tax rates.

24 The so-called 'general equilibrium theory' and the supposed norm of market efficiency is based on this phantom. However, even if we were to bracket this phantom character, that theory is based on non-neutral assumptions. These have been set out by Hahn, for example in his 1981. (This source is relevant because Hahn was an expert working himself in the field of general equilibrium theory.) 
- Regarding taxation of products it is difficult or even impossible to build progression into the taxes other than in a rough way, such as a lower rate for common foods.

- For corporate profit taxes progression is possible, for example if the progression would start at a threshold related to the number of labourers employed or via so-called tax brackets. (Nevertheless beyond such brackets the usual corporate taxes are most often a flat percentage. $)^{25}$ Another possibility would be to differentiate the rate for retained versus distributed profits.

- The design of a fine-tuned progressive taxation is easiest for a wages tax, and generally for any final income tax of households.

Progressive tax rates: profits and savings

In terms of the effect of taxes on the profits of enterprises, the exposition in $8 \mathrm{D}_{4}$ implies that a progressive tax on personal income assists integral profits. The more skewed the distribution of this income, the more savings press down profits. $^{26}$ Thus progressive personal income taxes support enterprises: their rate of profit and so investment and employment.

This puts on the state's agenda the dilemma as to whether it is primarily concerned with the interests of enterprises or rather with the high-income categories. Essential in this respect is the long-standing ideological supposition that investment would require savings $(3 \S 2,3 \S 3,3 \S 9)$. For many this ideology functions as an argument to favour a skewed distribution of income. ${ }^{27}$

\section{Contingency of the redistribution of income and wealth?}

Seemingly the existence of the capitalist system does not pertain to a particular personal distribution of income and wealth. The capitalist system provides plenty of opportunity to purposely build in inequality of income and wealth. On the other hand, it might seem that the capitalist system is compatible with

25 Sometimes small corporations are favoured by a flat lower rate up to some threshold measured for example in amount of profit.

26 This is different for wages income (including that of the management) and current capital income. However, to the extent that the income categories fall under the same 'income taxes' this difference is not effective in practice. Regarding capital income, and to the extent that the consumption out of this income is stable (as, in a Kaleckian vein, has been assumed throughout) saving out of capital income is reflected in the issue of new bonds and shares of enterprises (see $3 \S 6$, Circuit 3.13). For this category, however, and to the extent that enterprises issue relatively more bonds than shares, the liabilities position of enterprises is affected.

27 Keynes was very much aware of this, calling 'the rentier' a 'functionless investor' (Keynes 1936, Chapter 24, section II). (He means a functionless financier or 'portfolio investor'.) 
an equal distribution of income or 'even' one where the unattractive work (for example, garbage collection - in general the bottom of the current wages ladder) is better paid than the more attractive work.

In fact the interest of the upper income and wealth classes has been served in the past, and is served currently, by the building in of a considerable skewedness in the distribution of income and wealth. ${ }^{28}$ However, this skewedness is constrained by the compliance of the majority of the people $(2 \S 5,2 \S 7,2 \S 7$-b, $6 \S 5,7 \S 17)$, and particularly also a wages ladder and a disposable income ladder that gains the overall compliance of also the upper-lower and the middle classes (say, the middle 6o\% of the income distribution - income deciles $3-$ $8)$. However, whereas this requirement is not contingent, the gaining of this compliance is.

For this gaining of compliance, ideology is a prominent factor: the higher income classes do (not) deserve their income for such and such reasons. The key part of this ideology is the phantom of the market, which in all official statistics is taken as a point of departure, and so as a reference point. When that is taken as the reference point, income is seen to be taken away from the upper classes so as to be redistributed to the lower ones. It is a crucial part of this ideology that the prior production and appropriation of surplus-value is neglected: the market outcome of it is the statistical starting point and reference point.

8§11-a Amplification. Examples of distributions of household income in the OECD-21 around 2015

Graph 8.13 shows an example of a deciles distribution of the income of households for various income measures. (In a deciles distribution the population of households is ranked from low to high income, and next divided into ten groups, each of $10 \%$ of the population.) 'Market income' (or primary income) is the income before any redistribution. 'Gross income' is the market income after social security transfers. 'Disposable income' is the gross income after direct taxes. These three measure what households actually receive at some point. There is also a fourth measure around, which is 'equivalised disposable income'. For this measure households are standardised as to the number of members in a household; adults have a higher weight than children. If these four measures are compared, it makes a difference which one is the basis for the ranking of the deciles.

The example is of the UK (Graph 8.13) - see Table 8.18 for its OECD-21 income rank.

28 As before, I take class as an objective category - in this case statistical classes of the distribution of income and wealth. 
GRAPH 8.13 Distribution of income: Market, Gross and Equivalised disposable income households by deciles, case of the UK 2015

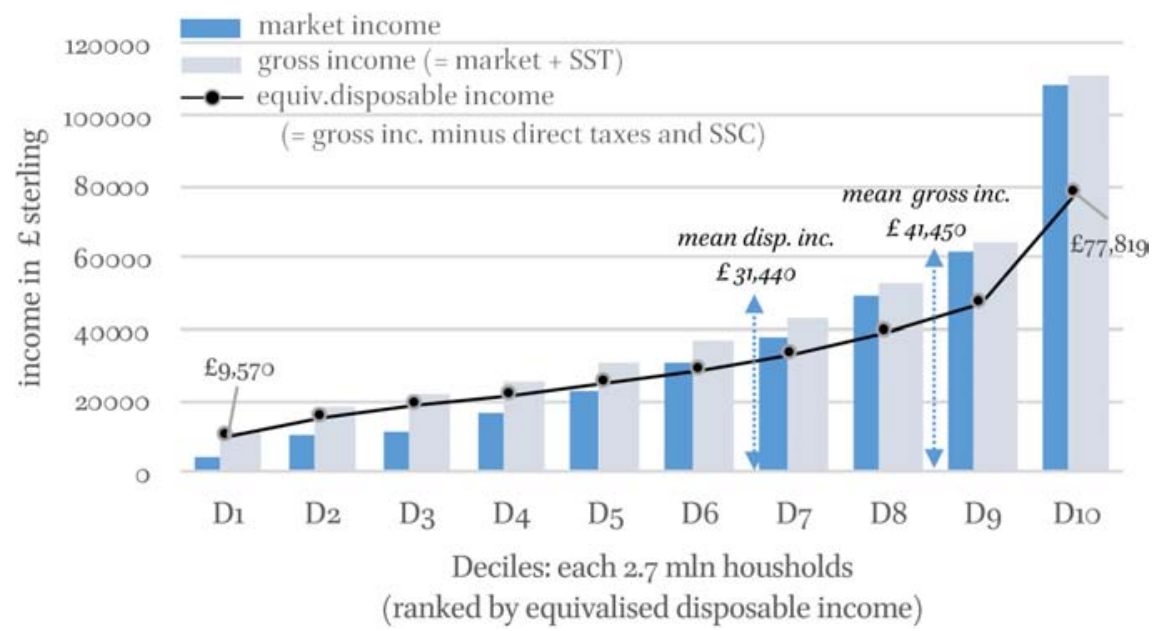

DATA SOURCE: Office for National Statistics (UK), Dataset 'The effects of taxes and benefits on household income' 2015/16, Table 2a (release date 25 April 2017)

TABLE 8.14 Decile shares in total income of each category: UK 2015 (re. Graph $8.13)$

\begin{tabular}{lcccccccccc}
\hline Shares & D1 & D2 & D3 & D4 & D5 & D6 & D7 & D8 & D9 & D10 \\
\hline market inc. & $1 \%$ & $3 \%$ & $3 \%$ & $5 \%$ & $7 \%$ & $9 \%$ & $11 \%$ & $14 \%$ & $17 \%$ & $31 \%$ \\
gross inc. & $3 \%$ & $4 \%$ & $5 \%$ & $6 \%$ & $7 \%$ & $9 \%$ & $10 \%$ & $13 \%$ & $16 \%$ & $27 \%$ \\
eq. disp. inc. & $3 \%$ & $5 \%$ & $6 \%$ & $7 \%$ & $8 \%$ & $9 \%$ & $10 \%$ & $12 \%$ & $15 \%$ & $25 \%$
\end{tabular}

DATA SOURCE: As for Graph 8.13

We see in Graph 8.13 and Table 8.14 that on average the largest redistributive effect results from social security transfers (SST) rather than from taxes. This can be better seen from Graph 8.15. This graph shows for an average of up to 20 OECD-21 countries the Gini measure for each income category. The Gini index (or Gini coefficient) is a common measure for the skewedness of a distribution. It adopts a scale of o to 1 , the number o indicating complete evenness of the distribution, and the number 1 maximal skewedness (all income is owned by one unit of the population). This graph shows that social security transfers (ssT) are the main factor bringing about a less skewed distribution of income (the difference between the top and the middle bar for the data since 2000). In 2015 it accounted for $3 / 4$ of the difference. 
GRAPH 8.15 Distribution of household income (equivalised): Gini indices of (a) market income; (b) income post social security transfers; (c) income post direct taxes; 1985-2015; averages of 4-2O OECD-21 countries

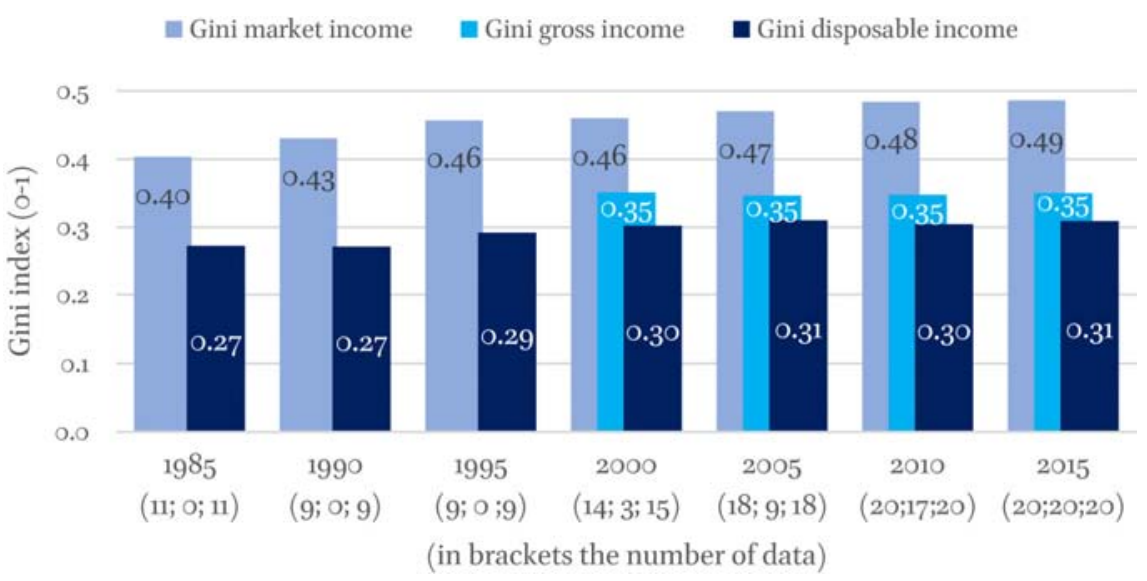

DATA SOURCE: OECD, dataset Income Distribution and Poverty; accessed 8 October $2017 .{ }^{29}$ Year as indicated or nearest year available ${ }^{30}$

Graph 8.15 also shows that in the three decades from 1985 to 2015 , the Gini for market income increased by $21 \%$ and that for disposable income by $13 \%$. This is also the period in which the increase in state expenditure on ssT moderated (see $7 \S 17-a$, Graph 7.10).

Note that the Gini measure is not very sensitive to the extremes of the distribution. These are more properly measured by, for example, the ratio of the top decile over the bottom decile or of the top quintile (20\% groups) over the bottom quintile. Nevertheless, even for the Gini we see in terms of the change in these decades a redistribution of income from the broad bottom to the broad top.

The social security transfers in the OECD-21 do not prevent that a considerable part of the households has an income below the poverty line. The poverty line is variously defined. Here I show data for the poverty line that is defined as

29 http://stats.oecd.org/viewhtml.aspx?datasetcode=IDD\&lang=en. The following link provides brief OECD definitions of various distributional measures: https://data.oecd.org/ inequality/income-inequality.htm.

30 The Gini for gross income before 2000 is only available for one or two countries (data accessed in October 2017). The data used for the graph are those of the income definition 2012 from when it is available for a country (most often the effects of the 2011 versus 2012 definitions are rather small). 
half the median household income of the total population. This measure takes account of the degree of access to the goods and services that are regarded as customary in any county in a particular year. (Here the average of the OECD21.) The poverty rate is defined as the number of households below this line relative to the total population of households. Graph 8.16 shows this poverty rate before and after transfers and direct taxes - again for equivalised households.

GRAPH 8.16 Poverty rate before and after transfers and taxes, 1985-2015; averages of 9-21 OECD-21 countries

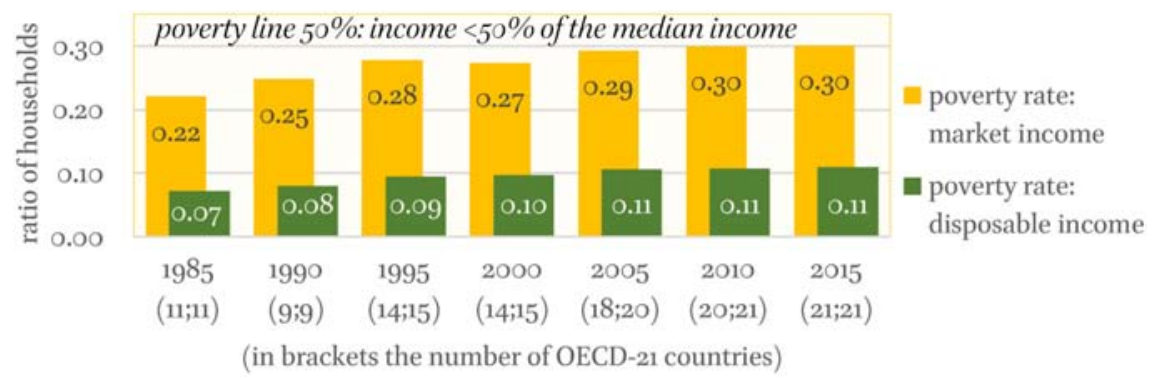

DATA SOURCE: See Graph 8.15. Year as indicated or nearest year available ${ }^{31}$

Graph 8.16 shows that between 1985 and 2015, the before and the post transfers and taxes poverty rates increased by $36 \%$ and by $52 \%{ }^{32}$ It is certainly relevant that in the OECD-21, $11 \%$ of households lived under the poverty line. It is also relevant that without social security provisions this would be $30 \%$ of households, which, presumably, would be unsustainable in terms of legitimation.

Table 8.17 shows for three OECD-21 countries the social security transfers (SST) as a percentage of households' gross income. The last column indicates the average for all households, and the other columns indicate the distribution over the household income deciles. These countries are chosen on the basis of the diversity of their OECD-21 skewedness ranking of gross income in 2015 (top, middle and bottom, as shown in Table 8.18). For each of these countries

31 The data are those of the income definition 2012 from when it is available for a country.

32 In 2010 the poverty gap - that is, the average shortfall from the poverty line - was for the OECD-21 at 30\%. In 2010 the median disposable income (equivalised household) for, e.g., Germany was $€ 20,535$ per year, with its poverty gap at $24 \%$. Thus the poverty line for this country was at $€ 856$ per month, and the average poor household disposed over $€ 65$ o per month. (For the USA this last figure was $\$ 920$.) 
the ssT design is quite different. In each case, however, it is the 6th decile that receives about the country's average ssT. Thus it is roughly $\mathrm{D}_{1}-\mathrm{D}_{5}$ that benefits from average increases in SST (ceteris paribus the design), and vice versa for decreases. I will further comment on this in Chapter 10 (10\$12).

TABLE 8.17 All household share (\%) and deciles share (\%) of social security transfers in gross income: UK 2015, Netherlands 2014 and Norway 2015

\begin{tabular}{lrrrrrrrrrrr}
\hline & D1 & D2 & D3 & D4 & D5 & D6 & D7 & D8 & D9 & D10 & All \\
\hline UK & $60 \%$ & $47 \%$ & $48 \%$ & $36 \%$ & $25 \%$ & $17 \%$ & $13 \%$ & $8 \%$ & $5 \%$ & $2 \%$ & $15 \%$ \\
Netherlands & $122 \%$ & $99 \%$ & $93 \%$ & $76 \%$ & $45 \%$ & $24 \%$ & $16 \%$ & $11 \%$ & $7 \%$ & $6 \%$ & $25 \%$ \\
Norway & $53 \%$ & $42 \%$ & $34 \%$ & $27 \%$ & $22 \%$ & $19 \%$ & $16 \%$ & $13 \%$ & $11 \%$ & $6 \%$ & $18 \%$ \\
\hline
\end{tabular}

DATA SOURCES: UK (as for Graph 8.13); Netherlands (Statistics Netherlands (CBS), Inkomensgroepen; particuliere huishoudens naar diverse kenmerken); ${ }^{33}$ Norway (Statistics Norway, Statbank, Income and wealth statistics for households, Composition of total household income and equivalent after-tax income (per cent), by contents, time and equivalent after-tax income). ${ }^{34}$ Accessed 21 October 2017

TABLE 8.18 OECD-21 income rank of the UK, Netherlands and Norway in 2015 (rank 1 is very skewed, rank 20 is skweded) ${ }^{35}$

Market income Gross income Disposable income

\begin{tabular}{lrrr}
\hline UK & 5 & 3 & 2 \\
Netherlands & 15 & 11 & 10 \\
Norway & 19 & 18 & 19 \\
\hline
\end{tabular}

DATA SOURCE: OECD, Dataset Income distribution and poverty (accessed 8 October 2017)

$33 \mathrm{http} / /$ statline.cbs.nl/Statweb/publication/?DM=SLNL\&PA=71013NED\&D1=0-2\&D2= $\mathrm{a} \& \mathrm{D}_{3}=\mathrm{O}-10 \& \mathrm{D}_{4}=\mathrm{O} \& \mathrm{D}_{5}=\mathrm{l} \& \mathrm{HDR}=\mathrm{G}_{4}, \mathrm{G1}, \mathrm{T} \& \mathrm{STB}=\mathrm{G}_{3}, \mathrm{G} 2 \& \mathrm{VW}=\mathrm{T}$ ( data 8 February 2017 ; accessed 10 October 2017).

34 https://www.ssb.no/statistikkbanken/selectout/pivot.asp?checked=true (accessed 21 October 2017).

35 No 2015 data for Japan. 
8§11-b Amplification. The development of the top 5\% and the top 10\% shares of income between 1910 and 2010 for averages of current OECD-21 countries

The great advantage of data from the OECD is that country data are based on uniform definitions that guide the work of the national statistical bureaus. For long run historical data this is quite different, because data collection from the past cannot be remade. We have what we have, and efforts at uniformity must be made via estimates. Income data of the non-recent past are mostly based on data from taxation authorities, which have been devised not on the basis of theoretical definitions (such as the components of 'gross income'), but rather on the varying legislation of taxation (tax codes) between countries and over time. Thus, for example, the 'tax units' (individual, household and household composites) diverge between countries and over time.

The data used for Graph 8.19 are based on the painstaking work of many people from different countries that got together to construct the 'World wealth and income database' (best-known amongst the general public is Thomas Piketty, and among economists also Emmanuel Saez and Tony Atkinson). Incidental data on top incomes (and wealth) go back to the early nineteenth century, but more or less continuous series for several countries date from the early twentieth century. (See Roine and Waldenström 2014, pp. 12-22, or Roine and Waldenström 2015, section 2.1, for a brief description of the data and the problems thereof.) In sum, the data used are of an approximation of 'gross income', the tax unit being mostly individuals (personal income). The focus is on top incomes because given the historical tax codes, these are the most reliable (though for top income shares, the income of the total population has to be estimated).

Graph 8.19 shows that each of the top shares moderately decreased until 1950 and next far more steeply from 1950 to 1980 . In the following three decades we see a steep increase, reaching in 2010 to above the 1950 levels (considering three-decade periods this steep increase moved faster than the earlier steep decrease).

Very roughly the steep decrease period coincided with the steep increase in SST that was shown in Graph 7.10 (probably, as SsT data for 1940 and 1950 are lacking) - the sst increase turning to a moderate one after 199o. Whilst this does not explain all of it, it does seem to explain some of it. 
GRAPH 8.19 Distribution of income: shares of the top $10 \%$ and the top $5 \%$ in the total personal income, 1910-2010; averages of up to 14 current oECD countries ${ }^{36}$

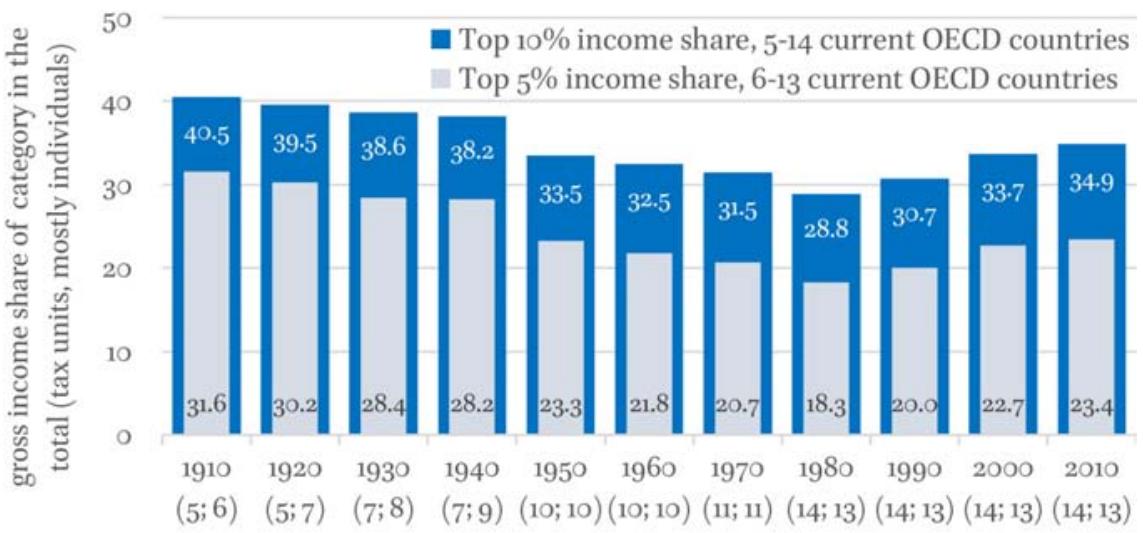

(in brackets: the number of countries top $10 \%$ and $5 \%$ )

DATA SOURCE: World wealth and income database (decade years or nearest year available) ${ }^{37}$

\section{$8 \S 12 \quad$ The after-tax resulting distribution of wealth}

- The distribution of wealth

The constellation of taxes and their design (8§11) results in a particular distribution of wealth. Given that taxation on wealth is usually accounted as a deduction from current income, the prevailing distribution of wealth is the end result of:

- first, the revaluation or devaluation of previous wealth;

- second, taxation of wealth and current income;

- third, current income saved.

The distribution of wealth tends to be far more skewed than the distribution of income (Amplification 8§12-a).

- The distinction between capital and wealth, and the distribution of capital

'Wealth' refers to all durable entities or claims that have a monetary value. 'Capital' is a form of wealth. However, this does not mean that all wealth is 'capital'. Capital is a form of wealth geared to production, with the purpose of selling

36 Australia, Canada, France, Germany, Ireland, Italy, Japan, Netherlands, Norway, Portugal, Spain, Sweden, Switzerland, USA. (There are data available for other countries: Denmark, New Zealand and the UK. However, their base of households differs too much from that of the current group for calculating a consistent average.)

http://www.wid.world/ (accessed 2o October 2016). 
that production so as to make a profit. Directly this applies to 'active capital' (Figure 3.2a, in $3 \S 1$, summarises the distinction between active and passive capital). In one of these active or passive forms of capital, a category of households is the owner of capital (for the non-incorporated enterprises these households are the owner of active capital).

Note that whereas bonds issued by enterprises are a form of passive capital, bonds issued by the state are not capital (from the point of view of the financier this regards merely a matter of degree of risk).

Capital ownership tends to be concentrated at the top of the distribution of wealth - in fact the top $10 \%{ }^{38}$ Thus within the wealth skewedness, the distribution of capital is even more skewed (Amplification 8§12-b).

The distribution of wealth is a matter of monetary distribution. If we look at its capital component it is still a monetary distribution, but it is also a distribution of potential or actual economic power.

Unless stated otherwise, 'wealth' in the amplifications of this section refers to 'net wealth', that is, assets minus debts. These amplifications are:

$8 \S 12$-a. An estimate for the distribution of wealth of the OECD-21 for 2015 .

$8 \S 12-\mathrm{b}$. The distribution of wealth and its components: case of the Netherlands 2015 .

$8 \S 12$-c. Top wealth shares of 19 OECD-21 countries around 2014.

$8 \S 12$-d. The top $5 \%$ and top $10 \%$ shares of wealth between 1910 and 2010.

$8 \S 12-$ e. Taxation of inheritance of wealth.

$8 \S 12-\mathrm{a} \quad$ Amplification. An estimate for the distribution of wealth of the OECD-21 for 2015

Country data about wealth distribution are most often not collected on an internationally standardised basis. Shorrocks, Davies and Lluberas (2015) provide an estimate of the global distribution of wealth. In Graph 8.20 I have used their estimates for the OECD-21 countries. It can be seen that the wealth distribution over deciles is far more skewed than the income distribution over deciles (compare Graph 8.13 in $8 \S 11-\mathrm{a}$ ). For example, whereas in 2010 the ratio of the mean to the median disposable income is 1.1, the ratio of the mean to median wealth is 2.6 (2010 and 2015 estimate).

38 The relative concentration increases to the extent that we consider the top $5 \%$, the top $1 \%$ and so forth. For the top 10\%, $5 \%$ and $1 \%$ Murtin and Mira d'Ercole show this for 18 OECD counties around 2010 (see Murtin and Mira d'Ercole 2015, Figures 2 and 3). 
GRAPH 8.20 Wealth distribution: shares of deciles and of top 5\% and top $1 \%$, estimate for 2015; average of OECD-21

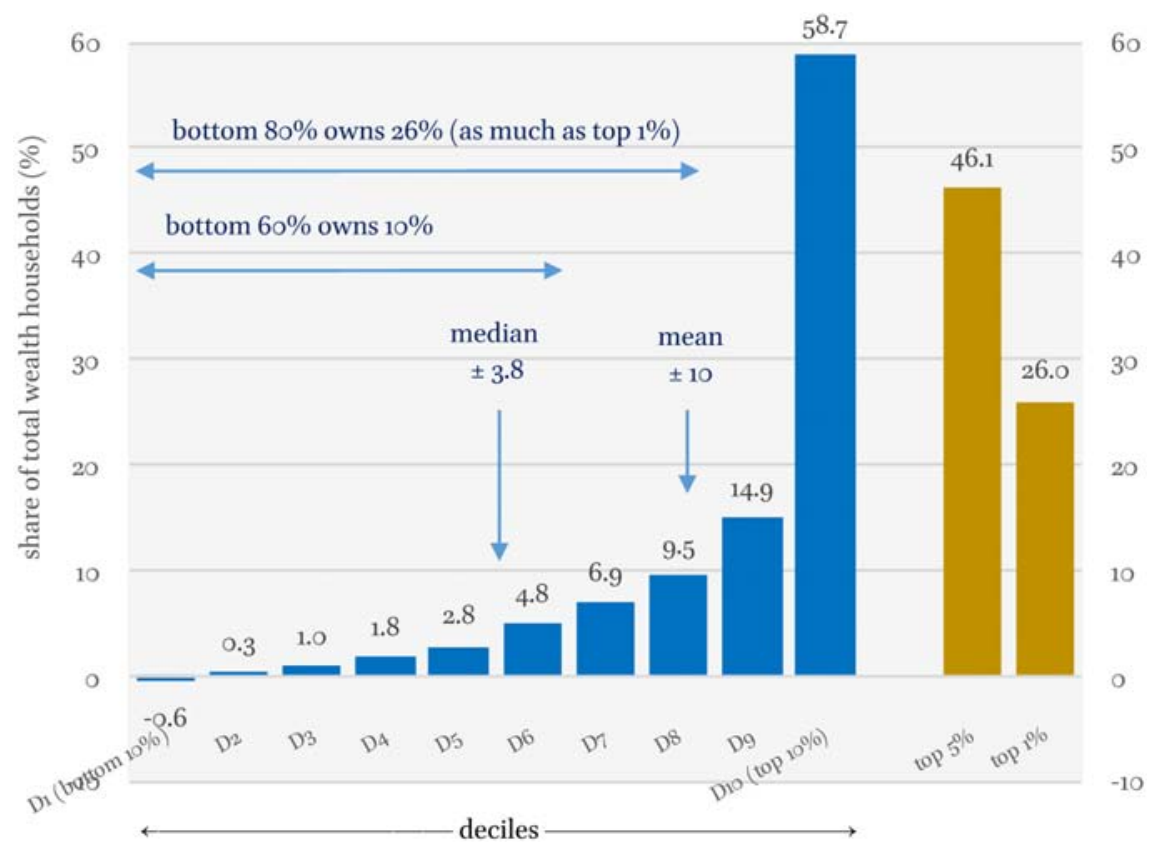

DATA SOURCE: Shorrocks, Davies and Lluberas 2015, p. 149, Table 6-5

The distance between the median and the mean is a simple measure for the skewedness of the (wealth) distribution.

The following amplifications are about the factual distribution of wealth. The next two sentences are on facts about beliefs. According to research on beliefs about the distribution of income and of wealth in the USA, the average interviewee (in 2011) thinks that these distributions are far less skewed than they are in fact. ${ }^{39}$ On the other hand, $61 \%$ of interviewees (in 2013) believe that the USA economic system favours the wealthy. ${ }^{40}$

8§12-b Amplification. The distribution of gross wealth and its components: case of the Netherlands 2015

This amplification presents the distribution of the main components of gross wealth for the Netherlands in 2015 - assets and debts (see Graph 8.21). Of the 19

39 https://www.scientificamerican.com/article/economic-inequality-it-s-far-worse-thanyou-think/ (Nickolas Fitz, Scientific American, 31 December 2015).

40 http://www.pewresearch.org/fact-tank/2013/12/o5/u-s-income-inequality-on-rise-fordecades-is-now-highest-since-1928/ (Drew Desilver, Facttank, 5 December 2013). 
OECD-21 countries for which the OECD has data available for around 2014, the Netherlands ranks, regarding the wealth share of each of the top $10 \%$, top $5 \%$ and top $1 \%$, second in skewedness after the USA. ${ }^{41}$

The general picture of this graph is no different from the previous one. However, its main point is that we now see the degree of concentration of the capital component of wealth at the top of the distribution: in 2015 the top $10 \%$ owns $89 \%$ of the total capital of households.

GRAPH 8.21 Deciles distribution of gross wealth and its components: the Neth-
erlands 2015

1000

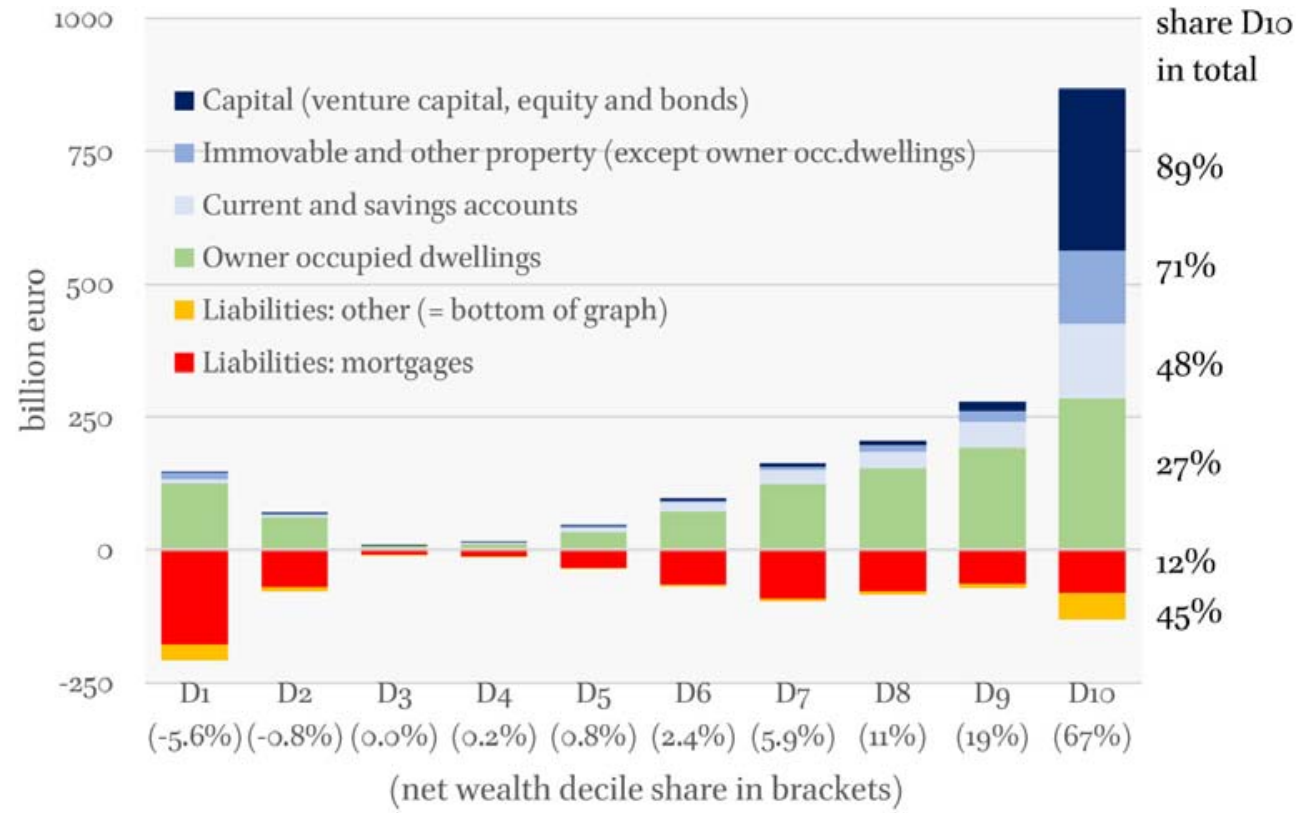

DATA SOU RCE: Statistics Netherlands (CBS): 'Vermogen van huishoudens; huishoudenskenmerken, vermogensbestanddelen', 2015 (release date 7 February 2018$)^{42}$

The Dio liabilities reveal, mainly, that the wealthiest class uses debt as an amplifier of wealth (in Chapter 3 , Appendix $3^{B}-4$, I called this 'finance doubling').

41 OECD dataset Wealth (net wealth) http://stats.oecd.org/index.aspx?DatasetCode= WEALTH (accessed 29 Jan 2018).

42 Accessed 7 February 2018. http://statline.cbs.nl/Statweb/publication/?DM=SLNL\&PA $=83834 \mathrm{NED} \& \mathrm{D} 1=1-3 \& \mathrm{D}_{2}=0,5_{1}-6 \circ \& \mathrm{D}_{3}=0-14 \& \mathrm{D}_{4}=9 \& \mathrm{HDR}=\mathrm{G}_{3}, \mathrm{~T} \& \mathrm{STB}=\mathrm{G} 1, \mathrm{G} 2 \& \mathrm{VW}=\mathrm{T}$. 
The negative wealth share of the first two deciles reveals an insufficient dwellings coverage of mortgages. Especially for the D1 it also reveals overcrediting to small non-incorporated enterprises.

(In 2015 the total net wealth of households was $160 \%$ of GDP; for D1o this was $108 \%$.)

8§12-c Amplification. Top wealth shares of 15 OECD-21 countries around 2010

The OECD remarks on its website that until it issued guidelines for the collection of wealth data in 2013, there was no agreed standard that statistical offices could use for collecting these data. ${ }^{43}$ The data that I have used in Table 8.22 for the top-wealth shares are probably the only ones currently available that have been collected on a uniform base.

Table 8.22 shows, as usual, OECD-21 averages (insofar as they are available). However, as an exception this time I also specify the top and bottom deviations from the average.

TABLE 8.22 Top wealth shares of 19 OECD-21 countries in or around $2014^{\dagger}$

Share top 10\% Share top $5 \%$ Share top 1\%

\begin{tabular}{llll}
\hline average OECD-19 & 52.4 & 38.6 & $18.6^{\ddagger}$
\end{tabular}

top skewed distributions

(with their rank in brackets)

$\begin{array}{llll}\text { USA (2013) } & 78.2(1) & 65.9(1) & 37.6(1) \\ \text { Netherlands (2015) } & 68.3(2)^{44} & 52.5(2) & 27.8(2) \\ \text { Denmark (2015) } & 64.0(3) & 47.3(3) & 23.6(5) \\ \text { Germany (2014) } & 59.8(4) & 46.3(4) & 23.7(4) \\ \text { Austria (2014) } & 55.6(5) & 43.5(5) & 25.5(3)\end{array}$

43 See also Murtin and Mira d'Ercole [OECD] 2015.

http://www.oecd.org/std/household-wealth-inequality-across-OECD-countriesOECDSB21.pdf.

44 This figure deviates from that shown in Graph 8.21 (67.1\%), which stems from a different release date. For the country comparison only the oECD data are relevant. 
TABLE 8.22 Top wealth shares of 19 OECD-21 countries (cont.)

\section{Share top $10 \%$ Share top $5 \% \quad$ Share top $1 \%$}

least skewed distributions

(with their rank in brackets)

\begin{tabular}{lllr}
\hline Finland (2014) & $45.2(15)$ & $31.4(15)$ & $13 \cdot 3(14)$ \\
Italy (2014) & $42.8(16)$ & $29.7(17)$ & $11.7(16)$ \\
Belgium (2014) & $42.5(17)$ & $29.7(16)$ & $12.1(15)$ \\
Greece (2014) & $42.4(18)$ & $28.8(18)$ & $9.2(18)$ \\
Japan (2014) & $41.0(19)$ & $27.7(19)$ & $10.8(17)$ \\
\hline
\end{tabular}

$\dagger$ OECD-21 minus Sweden and Switzerland (and for the top $1 \%$ of wealth also New Zealand). For each of these countries only 1-3 observations are available between 2009 and 2015 . The table is based on the data nearest to 2014 (which is the year for which data are most frequently available).

$\ddagger$ This column regards 18 countries (no data for New Zealand).

DATA SOURCE: OECD Dataset Wealth (net wealth) ${ }^{45}$

Because of their social security constellation, the Netherlands, Germany, and Austria have been classified as 'Rhineland capitalist countries'. It can be seen from Table 8.22 that such a constellation is far from detrimental to their, in terms of wealth, capitalist upper class. ${ }^{46}$

45 http://stats.oecd.org/index.aspx?DatasetCode=WEALTH (accessed 29 January 2018).

Anticipating the next amplification, the following table compares two OECD data from the second row of Table 8.22 with the figures of amplifications $8 \S 12$-a and $8 \S 12$-d.

\begin{tabular}{lcc}
\hline Source & \multicolumn{2}{c}{ Top shares wealth (\%) } \\
top 10\% & top 1\% \\
\hline $\begin{array}{l}\text { OECD data, 18-19 countries [around 2014] } \\
\text { Roine and Waldenström (WWID data), 6-7 countries } \\
\quad \text { around 2010] }\end{array}$ & 52.4 & 18.6 \\
$\begin{array}{l}\text { Shorrocks, Davies and Lluberas, estimate 21 countries } \\
\quad[\text { for 2015] }\end{array}$ & 58.7 & 21.9 \\
$\quad$ & & \\
\hline
\end{tabular}

$46 \quad$ See also Bavel and Frankema 2013. 
8§12-d Amplification. The top 5\% and top 10\% shares of wealth between 1910 and 2010

The historical OECD averages that I present in this amplification are based on data collected by Roine and Waldenström (2014). As these authors indicate, 'the empirical literature on wealth inequality is still limited, particularly when it comes to the long run perspective' (p. 40). For various problems of the data I refer to these authors, and for what they did about these when possible (pp. 409) ${ }^{47}$ However, many of these problems do not just relate to long run historical data. ${ }^{48}$

GRAPH 8.23 Distribution of wealth: top wealth decile and percentile as share of the total private wealth, 1910-2010; 6-10 current OECD countries ${ }^{49}$

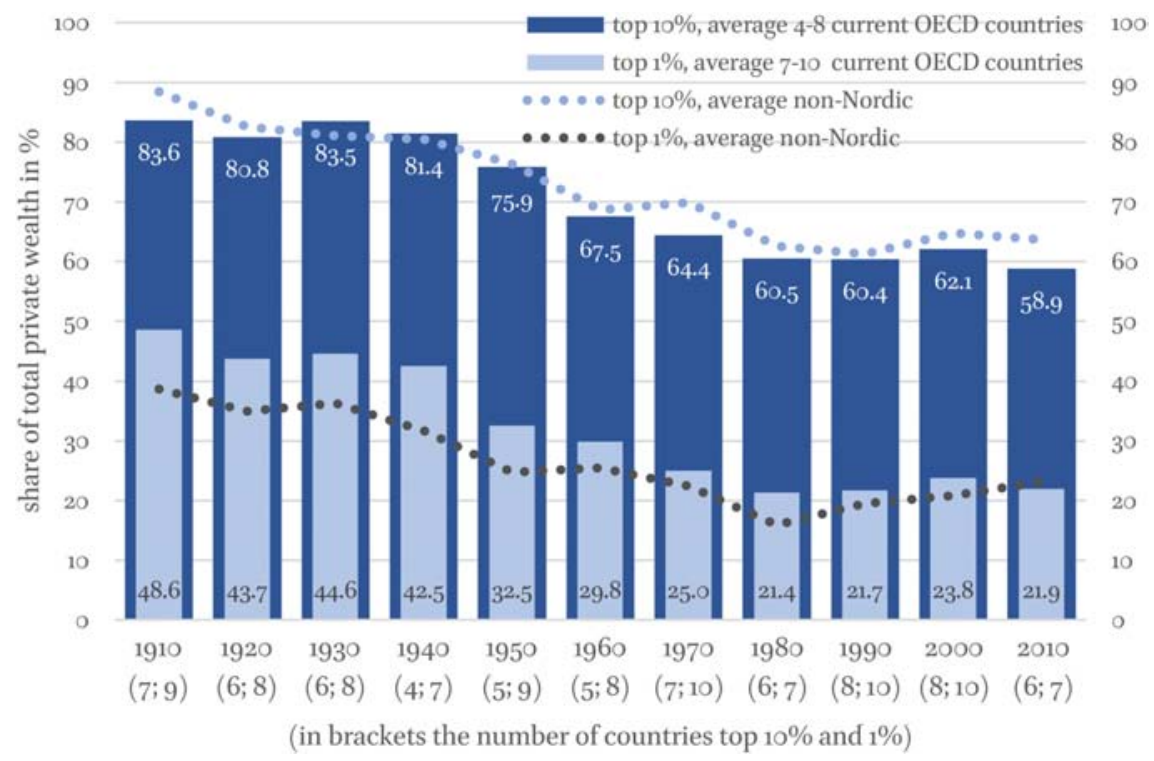

DATA SOURCE: Roine and Waldenström 2014. Country decade years or the nearest year avail$\mathrm{able}^{50}$

47 Roine and Waldenström 2015, pp. 40-9. For the sources of the data that the authors collected, see their Table A1, pp. 141-2.

48 For the detection of problems of recent data (such as those collected by the EU), see Salverda 2015 , pp. 7-14.

49 Top wealth decile: Denmark, Finland, France, Norway, Sweden, Switzerland, UK, USA. Top wealth percentile, idem plus Australia and the Netherlands. The 'Nordic' countries are Denmark, Finland, Norway and Sweden.

5o http://www.uueconomics.se/danielw/Handbook.htm. The authors closed off their study 
Comparing the 2010 data from Roine and Waldenström with those of the OECD nearest to 2010 (see the table in the last but two footnote), it appears that for the data that overlap qua country $\left(5^{-6}\right)$, the OECD data are $10 \%$ lower for the top 10 and $20 \%$ for the top 1 (these are in percent, not percentage points of the shares). Hoping that the deviations are more or less consistent over time, the data from Roine and Waldenström can be used as an indicator of the trend see Graph 8.23 .

The Nordic countries (Denmark, Finland, Norway, Sweden) make up 19\% of the OECD-21 countries. However, for these wealth data this is 50\% (top decile) and $40 \%$ (top percentile). Therefore Graph 8.23 also shows the averages of the non-Nordic countries (dotted lines). Throughout this period the Nordic countries entertained above OECD-21 average social security provisions, but that did not impair their wealthiest classes in comparison with the OECD average. ${ }^{51}$

We see in Graph 8.23 that around 1910 the wealth share was starkly concentrated at the top. Throughout the period thereafter we see a continuous decrease in this concentration, and relatively more so for the top 1\% (19102010: a fall of $55 \%$; against a fall of $30 \%$ for the top $10 \%$ ). A substantial part of these shares decreases presumably has to do with the increase in the value of owner-occupied dwellings in the other deciles (especially deciles 7-9). Another important factor is taxes. Graph 8.24 shows how the top wealth share varies (or at least coincides) with total tax receipts (for details about the latter, see the text around Graph 8.4 in $8 \S 4-\mathrm{b}$ ). We see especially that with the bending off of the tax receipts from 1980 onwards, the top wealth share more or less stabilises. (Regarding the shares of wealth at hand, taxation seems a more important determinant than financial crises - see $2 \S 10-b$, Graph 2.11, for their occurrence in this period.)

This again would suggest not only the thesis that the state bought off the legitimation for the capitalist system, but that, in particular, the rich - that is, those who generally have a vested interest in the capitalist system - had to pay a price for it.

in 2014. For reasons of data consistency I have refrained from adding data for 2010 that are now available from other sources.

51 As indicated earlier, the same applies for 'Rhineland' countries such as Germany, the Netherlands and Austria, though for these from about 196o - and for the Netherlands until about 2000 when its social security provisions moved below the OECD-21 average. 
GRAPH 8.24 Distribution of wealth: the share of the top wealth decile as connected with total taxes, 1910-2010; averages of 7-8 current OECD countries

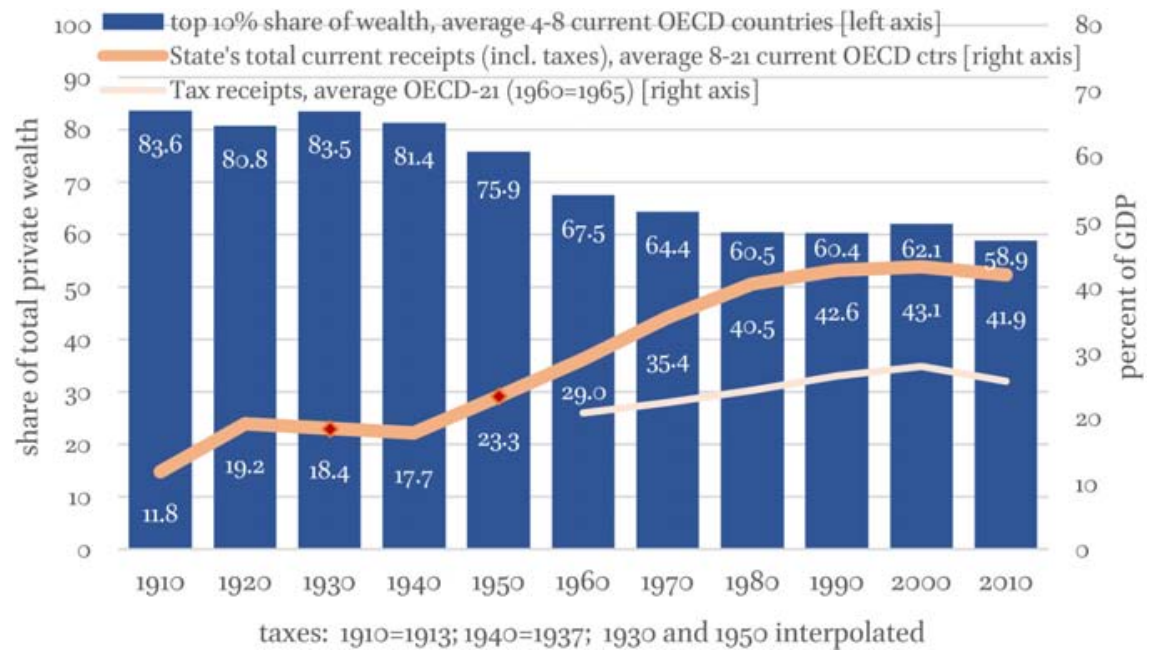

DATA SOURCE: Top wealth share, see Graph 8.23; Taxes and other state receipts, see Graph 8.4

8§12-e Amplification. Taxation of inheritance of wealth

It is often argued that taxation of wealth and of the inheritance of wealth is 'unfair' because taxes have already been levied on income. This argument neglects that the tax burden for the average household consists of two main components, namely direct taxes on income and indirect taxes on income spent. Thus the income spent is taxed twice. The non-spent income, that is, savings, is taxed once. The contra argument is that when savings are spent, the second round (indirect taxes) comes in. However, this contra argument neglects the fact that most of the top of the wealth (the top $10 \%$ and above) is never actually spent and is instead bequeathed.

Another contra argument is based on the presumed benevolence of saving as based on the loanable funds theory - this was already dealt with $(3 \S 6,3 \S 6-\mathrm{a}$, $3 \S 6-\mathrm{d})$.

Anyway, whereas direct taxes (including those on current wealth) are substantial for the top incomes and wealth layers, inheritance taxes seem moderate in the perspective of indirect tax rates (which are thus not levied on savings).

Unfortunately, long run data of effective inheritance tax receipts are lacking for the OECD-21. ${ }^{52}$ Graph 8.25 shows what is available for estate and inheritance 
taxes for the average of the OECD-21: data from 1965 onwards. ${ }^{53}$ It can be seen that the receipts from estate and inheritance taxes are not tremendous.

GRAPH 8.25 State receipts from estate, inheritance and gift taxes in \% of GDP, 1965-2015; average of OECD-21

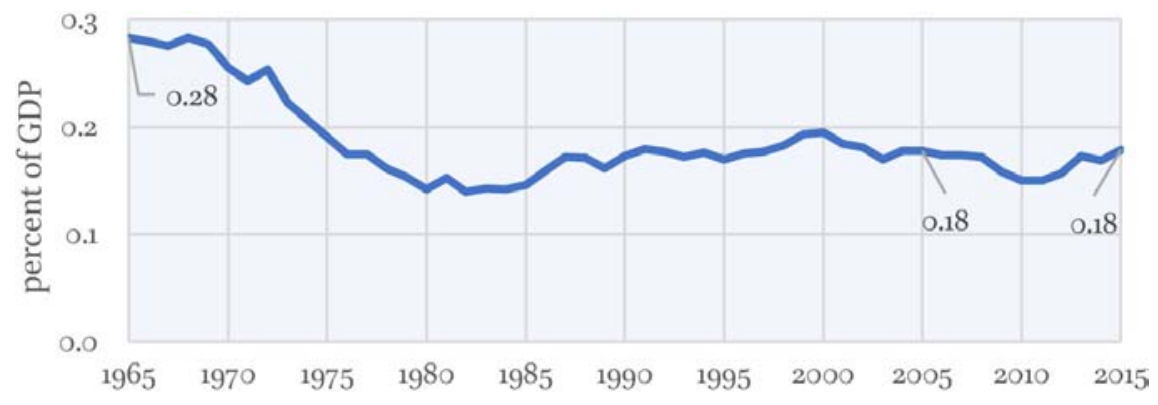

DATA SOURCE: OECD dataset Revenue Statistics - Comparative tables, series $4300^{54}$

\section{Summary and conclusions}

This chapter's Division 1 (state production) and Division 2 (finance of the state) provided concretising conditions of existence for the exposition of Chapters 6 7. All the other divisions presented concretising implications of these earlier chapters and divisions.

Economically, the state 'produces' the content of the economic rights framework and the frameworks furthering the accumulation of capital as presented in Chapters 6-7. For it, the state employs wage labour (i.e. civil servants) and purchases inputs from enterprises, but it tends to make no profits. Moreover,

Germany, UK and the USA). These are not irrelevant, but in the end it is the effective tax rates that count. https://www.quandl.com/data/PIKETTY/TS14_2-Top-inheritance-tax -rate-in-rich-countries-19oo-2013 - updated 29 April 2014; accessed 13 September 2017.

53 'An estate tax is applied to an estate before the assets are given to the beneficiaries. In contrast, an inheritance tax applies to assets after they have been inherited by someone. In the case of inheritance tax, each beneficiary may have to pay a different amount, depending on how much is inherited.' (Investopedia, January 2016 http://www.investopedia.com/ terms/e/estatetax.asp.)

54 http://stats.oecd.org/OECDStat_Metadata/ShowMetadata.ashx?Dataset=

REV\&ShowOnWeb=true\&Lang=en (last updated August 2017; accessed 21 January 2018). Investopedia (source previous footnote) mentions for the USA: 'As of 2016, the Internal Revenue Service (IRS) only requires estates with combined gross assets and prior taxable gifts exceeding $\$ 5.45$ million to file a federal estate tax return and pay estate taxes.' 
it distributes its produce for free as collective goods and services. Next to the state's expenditure on its production, its expenditures include transfers in the form of, mainly, social security and interest. (Division 1.)

Taxation is a necessary, and main, form of finance of the state. Next to this finance, the state may contingently collect social security contributions, and it may contingently collect other receipts (mainly) from royalties, sale of state services, and dividends of state-owned enterprises. Finally, the state may contingently borrow to finance any budget deficit (or lend in case of a surplus). The state's finance, in its particular forms, grounds the state's expenditures and hence the moments prior to it. (Division 2.)

All of the state's expenditures - though apart from the savings out of the state's wages and transfers - end up as expenditures with enterprises, and so also realise a major part of their surplus-value. Increases in state expenditure increase the production and validation of surplus-value - vice versa for expenditure decreases. (Division 3.)

Part of this state-accommodated surplus-value is distributed to the state via taxation of surplus-value (or narrower, taxation of profit). Thus, for enterprises in macroeconomic perspective, the benefits from state expenditure are in part offset by these taxes.

These taxes are the enterprises' costs of the state's granting and upholding their legal core economic rights to property and to the appropriation of surplusvalue, as well as of its accommodation of the accumulation of capital (that is, the costs of the seven legislative frameworks as presented in Chapters 67). Thus these are the costs for the state's accommodation of the enterprises' appropriation of surplus-value in general - not merely those that stem from extra surplus-value along with extra state expenditure.

In principle, all state expenditure might be financed by taxation of surplusvalue. In actual capitalist practice, however, the state acts such that enterprises 'share' the taxation with taxation of the wages income of labour, as well as of taxation of the surplus-value that enterprises distribute to owners of finance capital. From the perspective of labour, it is in fact immaterial where the taxes on surplus-value are levied (either at the point where these are generated within enterprises, or at the point where these are distributed). Thus in sum, the state acts such that enterprises and capital owners 'share' the taxation of surplus-value with the taxation of wages. (Division 4.)

Herewith the grounding of the capitalist state vis-à-vis the capitalist economy is completed.

At this point the exposition moves to the particular forms of taxation and their manifestation in the distribution of the income of households and in the distribution of the wealth of households. Households as such are, without fur- 
ther specification, not directly identified as workers' or capital owners' households, but rather as households that have some share in the income from wages or from surplus-value (recall 2 \$15-a's Graph 2.14 about the historical movement of the totals in the USA).

The main forms of taxation include taxes on profits, on property value and property income, on labour income and on products. In principle, the state might choose between these forms or combinations thereof. Some form of taxation being necessary, it is contingent which particular form or forms are actually applied, and to what extent.

Taxation has inevitably non-neutral distributive effects on income and wealth. This applies for the particular form of taxation and also for the design of tax rates (regressive, flat, progressive). More specifically, a flat tax rate is not more neutral than a non-flat one. Any actual form and design of taxation is inevitably based on a normative stance. This leaves unaffected the fact that with a more skewed distribution of income, more savings press down profits. Thus progressive taxes support enterprises: their rate of profit and so investment and employment. This puts on the state's agenda the dilemma as to whether it is primarily concerned with the interests of enterprises or rather with the privileges of the wealthy and high-income categories. The ideological supposition that investment would require saving is of key importance here.

The legitimation of the state in the compliance of the actors - and hence the legitimation of the capitalist system - tends to be shaped in at least some redistribution of income in favour of the lower echelons. However, this redistribution is mainly engendered via social security transfers rather than via effective progressive rates of taxation.

\section{Appendix 8A. Data and data sources of the graphs in chapter 8}

[Re 8§2-a.] Graph 8.2. Total state expenditure (general government) 1870-2015, in $\%$ GDP; average of 10 to 21 current OECD countries.

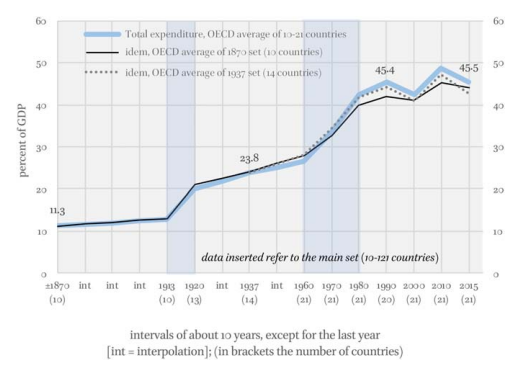

The graph shows the development of the average for: (1) a set of 10 countries for which data are available from 1870 to present (Australia, Austria; France, Germany, Italy, Japan, Norway, Switzerland, UK, US); (2) a set of 14 countries for which data are available from 1937 to present (the former plus Canada, Ireland, New Zealand

and Sweden); (3) the OECD-21 from 196o to present. 
Data sources. For 1870-1937 (Tanzi and Schuknecht 2000, Table I.1). I have omitted their data for 'central government' only, as this would disturb the comparison. For 1960-80 (Castles 2006, Table 1). To his data I have added the data for New Zealand, Norway and Switzerland from Tanzi and Schuknecht. For 199o-current (OECD, http://stats.oecd.org/OECDStat_Metadata/ ShowMetadata.ashx?Dataset=EO102_INTERNET\&ShowOnWeb= true\&Lang=en extracted 28 December 2017).

I have considered using data from Cusack and Fuchs 2002, who for the period $1870-1950$ collected total expenditure data from various sources (different from Tanzi and Schuknecht's) of 12-17 current OECD countries - more than the number of 10-14 that I have used from Tanzi and Schuknecht. Moreover, they also provide data for the years that I have interpolated. However, the disadvantage of their data (as for the full set that Tanzi and Schuknecht provide) is that these are mixes of General government and Central government data. Therefore I have declined using the Cusack and Fuchs data. ${ }^{55}$ Graph $8.2 A$ shows the data differences (I have included for all series the 1960 data from Castles), and Table 8.2B shows the various numbers of data for each year of the three sets.

GRAPH 8.2A Total state expenditure 1870-1950 in \% GDP for current OECD countries: comparison of data from Tanzi and Schuknecht with data from Cusack and Fuchs

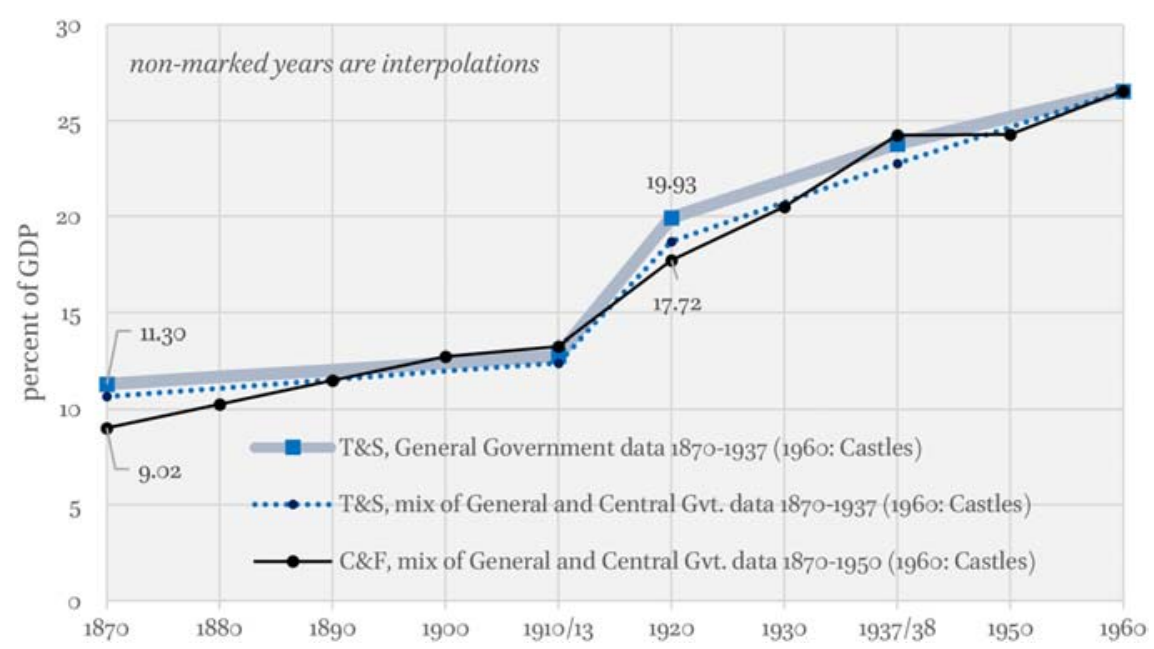

DATA SOURCES: Tanzi and Schuknecht 200o, Table I.1 and Cusack and Fuchs 2002, Table 1 and Appendix

55 For this graph - and the following ones - I have also declined using the database of Jordà- 
TABLE 8.2B Number of expenditure data 1870-1950: Tanzi and Schuknecht (2000) and Cusack and Fuchs (2002)

$\begin{array}{llllllllll}1870 & 188 & 189 & 1900 & 1910 / 13 & 1920 & 193 & 1937 / 38 & 195^{\circ}\end{array}$

\begin{tabular}{lccccccccc}
\hline T\&S, General Government & 10 &.. &.. &.. & 10 & 13 &.. & 14 &.. \\
T\&S, mix of Gen. and Centr. Gvt. & 12 &.. &.. &.. & 13 & 17 &.. & 17 &.. \\
C\&F, mix of Gen. and Centr.Gvt. & 12 & 11 & 11 & 11 & 14 & 14 & 14 & 16 & 18 \\
\hline
\end{tabular}

DATA SOURCES: SEE GRAPH $8.2 A$

Comparing the T\&S set for general government that I have used (row 1) with the C\&F set, the main differences are for 1870 and 1920. Because for one and the same country the datum for central government expenditure is smaller than that for general government expenditure, more central government data for one year generally implies that the average is pressed down further. C\&F have generally more data for one year; however, it is also the case that for $1870 \mathrm{~T} \& \mathrm{~S}$ have (row 1) data of Australia and Switzerland, and for 1920 of Australia and Ireland that $\mathrm{C} \& \mathrm{~F}$ do not have. This intensifies the general versus central government diversity for those years.

However, given these differences it is comforting to learn from the C\&F data that my decade interpolations seem not to miss up and downs for these intervals.

[Re 8§3] Graph 8.3. State employment as percent of total employment ${ }^{56}$ in comparison with state expenditure (each general government); averages of up to 21 current OECD countries, 1870-2015.

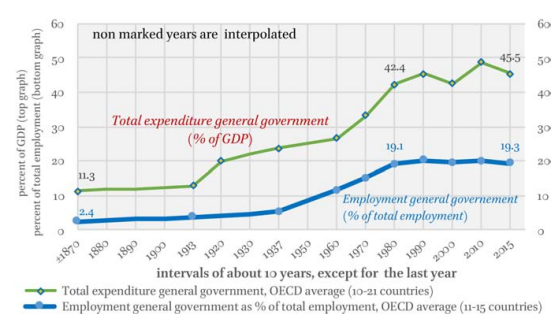

Employment general government, as a percentage of total employment (persons, civilian); average of 11-15 OECD countries 1870-2015. For 1870 and 1913: OECD-21 minus Canada, Denmark, Finland, Greece, New Zealand, Portugal, Spain. 1937: as for 1913, minus Australia and Belgium. 1960: OECD-21 minus Australia, Denmark, France, Greece,

Schularick-Taylor because it only pertains to central government. (Between states there is quite a divergence in what is allotted to the central or the lower government levels.)

$5^{6}$ Employment general government (excluding military employment and employment by public corporations), as a percentage of total employment (persons, civilian). 
Ireland, Japan, Norway, Spain. 1970-80: OECD-21 minus Australia, Austria, Germany, Greece, Ireland, New Zealand, Switzerland (Norway 1970=1972; UK 1970 $=1971$. 1990 onwards, as for 1980, plus Ireland).

Data sources: 1870, 1913, 1937 (Tanzi and Schuknecht 200o, Table II.2); 196o (OECD 1999, Table 2.13), though with Australia omitted (datum includes public enterprises) and with Canada and Italy added from Tanzi and Schuknecht; 1970-current (oECD http://stats.oecd.org/OECDStat_Metadata/ ShowMetadata.ashx?Dataset=EO1O2_INTERNET\&ShowOnWeb= true\&Lang=en - accessed 28 December 2017).

[Re 8§4-b] Graph 8.4. State receipts (general government) 1870-2015, in \% GDP: (a) total current receipts; (b) tax and social security receipts; (c) tax receipts. Averages of 8-21 current OECD countries.

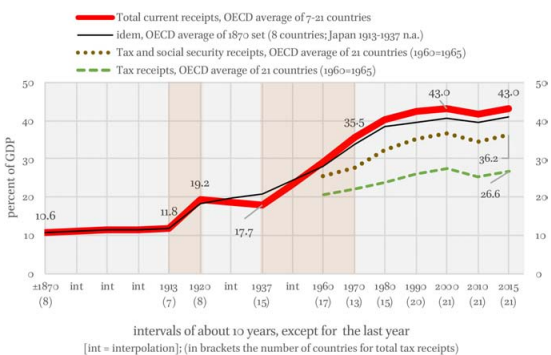

The two top lines show the development of the average total state receipts (general government) for two sets of current OECD countries: (1) a set of 8 countries for which 1870 data are available (Australia, France, Ireland, Italy, Japan, Norway, UK, USA); (2) the set of these counties, together with a through

time increasing number of countries - though with a gap for Japan in 1920 and in 1937, and for several countries in 1970 and 1980. (As follows: 1920 as for 1870 plus New Zealand minus Japan; 1937 plus Austria, Canada, Germany, Netherlands, Spain, Sweden, Switzerland; 196o plus Belgium, Finland, Japan, though minus New Zealand; 1970 as for 196o, minus Australia, Germany, Ireland, Sweden - Denmark 1970 $=1971 ; 1980$, as for 1970 plus Norway and Portugal; 1990 OECD-21 minus Greece - Germany 1990=1991; 2000 onwards, OECD-21.)

The bottom lines show the total tax and social security receipts for the full OECD-21. Note that there are these full data only from 1965. In the bottom graphs $1960=1965$.

Data sources. 1870-196o (Tanzi and Schuknecht 200o, Table III.1). I have omitted their data for 'central government' only, as this would disturb the comparison. Their data for 1960 have been updated for those countries for which the OECD Economic Outlook (2017-2) provides these. Total receipts 1970 onwards: OECD Dataset: Economic Outlook No. 102 - November 2017, General governments current receipts http://stats.oecd.org/index.aspx?DatasetCode= EO1O2_INTERNET. Tax and social contributions: OECD http://localhost/ OECDStat_Metadata/ShowMetadata.ashx?Dataset=REV\&ShowOnWeb= true\&Lang=en (updated 23 November 2017 - accessed 28 December 2017). 


\section{List of figures chapter 8}

Scheme 8.1 State expenditure and its finance (outline Chapter 8) 388

$8 \S 2$. The state's action in terms of state expenditure

Graph 8.2 Total state expenditure (general government) 1870-2015, in \% GDP; average of 10-21 current OECD countries 392

8§3. State production in terms of quantity of employment: state employment

Graph 8.3 State employment as percent of total employment in comparison with state expenditure (each general government); averages of up to 21 current oECD countries, $1870-2015 \quad 394$

8§4. Taxation and other main forms of finance of the state

Graph 8.4 State receipts (general government) 1870-2015, in \% GDP; average of 8-21 current OECD countries 397

Graph 8.5 Total state expenditure and total current receipts (general government) 1870-2015, in \% GDP; averages of up to 21 current OECD countries 398

8§5. State expenditure and production of enterprises

Table 8.6 Expenditure and current finance account of the state 399

Circuit 8.7 Destination of state expenditure 400

8§6. State expenditure and macroeconomic surplus-value

Circuit 8.8 Destination of state expenditure: purchases and saving 402

Table 8.9 Notation for the formal domains of Chapters 3 and $8 \quad 403$

$8 \S 7$. A profits tax: taxation of surplus-value

Figure 8.10 The distribution of surplus-value to financiers and to the state 409

8§9. The finance of social security: taxes and social security contributions

Graph 8.11 Finance of social security provisions 1970-2015, shares of social security contributions (SSC) and taxes; averages of OECD-21 414

Table 8.12 Finance of social security, and social security contributions as part of the gross wage 414

8§11. Forms and design of taxation, and their legitimation in compliance to a particular distribution of income

Graph 8.13 Distribution of income: Market, Gross and Equivalised disposable income households by deciles, case of the UK 2015419 
Table 8.14 Decile shares in total income of each category: UK 2015 (re. Graph 8.13) 419

Graph 8.15 Distribution of household income (equivalised): Gini indices of (a) market income; (b) income post social security transfers; (c) income post direct taxes; 1975-2015; averages of 4-20 OECD-21 countries 420

Graph 8.16 Poverty rate before and after transfers and taxes, 1985-2015; averages of 9-21 OECD-21 countries 421

Table 8.17 All household share (\%) and deciles share (\%) of social security transfers in gross income: UK 2015, Netherlands 2014 and Norway 2015422

Table 8.18 OECD-21 income rank of the UK, Netherlands and Norway in 2015422

Graph 8.19 Distribution of income: shares of the top $10 \%$ and the top $5 \%$ in the total income of individuals, 1910-2010; averages of up to 14 current OECD countries 424

$8 \S 12$. The after-tax resulting distribution of wealth

Graph 8.20 Wealth distribution: shares of deciles and of top $5 \%$ and top $1 \%$, estimate for 2015; average of OECD-21 426

Graph 8.21 Deciles distribution of wealth and its components: the Netherlands $2015 \quad 427$

Table 8.22 Top wealth shares of 19 OECD-21 countries in or around $2014 \quad 428$

Graph 8.23 Distribution of wealth: top wealth decile as share of total private wealth, 1910-2010; averages of up to 8 current OECD countries 430

Graph 8.24 Distribution of wealth: the share of the top wealth decile as connected with total taxes, 1910-2010; averages of 7-8 current OECD countries 432

Graph 8.25 State receipts from estate, inheritance and gift taxes in \% of GDP, 1965-2015; average of OECD-21 433

\section{Appendix 8A. Data and data sources of the graphs in chapter 8}

Re $8 \S 2$-a; $\quad$ Graph $8.2 \quad 435$

Graph 8.2A Total state expenditure 1870-1950 in \% GDP for current OECD countries: comparison of data from Tanzi and Schuknecht with data from Cusack and Fuchs 436

Table 8.2B Number of expenditure data 1870-1950: Tanzi and Schuknecht (2000) and Cusack and Fuchs (2002) 437

Re 8§3; $\quad$ Graph $8.3 \quad 437$

Re 8§4-b; Graph $8.4 \quad 438$ 